\title{
Carbon monoxide, methane and carbon dioxide columns retrieved from SCIAMACHY by WFM-DOAS: year 2003 initial data set
}

\author{
M. Buchwitz ${ }^{1}$, R. de Beek ${ }^{1}$, S. Noël ${ }^{1}$, J. P. Burrows ${ }^{1}$, H. Bovensmann ${ }^{1}$, H. Bremer ${ }^{1}$, P. Bergamaschi ${ }^{2}$, S. Körner ${ }^{3}$, and \\ M. Heimann ${ }^{3}$ \\ ${ }^{1}$ Institute of Environmental Physics (IUP), University of Bremen FB1, Bremen, Germany \\ ${ }^{2}$ Institute for Environment and Sustainability, Joint Research Centre (EC-JRC-IES), Ispra, Italy \\ ${ }^{3}$ Max Planck Institute for Biogeochemistry (MPI-BGC), Jena, Germany
}

Received: 27 January 2005 - Published in Atmos. Chem. Phys. Discuss.: 1 April 2005

Revised: 27 June 2005 - Accepted: 23 November 2005 - Published: 14 December 2005

\begin{abstract}
The near-infrared nadir spectra measured by SCIAMACHY on-board ENVISAT contain information on the vertical columns of important atmospheric trace gases such as carbon monoxide $(\mathrm{CO})$, methane $\left(\mathrm{CH}_{4}\right)$, and carbon dioxide $\left(\mathrm{CO}_{2}\right)$. The scientific algorithm WFM-DOAS has been used to retrieve this information. For $\mathrm{CH}_{4}$ and $\mathrm{CO}_{2}$ also column averaged mixing ratios $\left(\mathrm{XCH}_{4}\right.$ and $\left.\mathrm{XCO}_{2}\right)$ have been determined by simultaneous measurements of the dry air mass. All available spectra of the year 2003 have been processed. We describe the algorithm versions used to generate the data (v0.4; for methane also v0.41) and show comparisons of monthly averaged data over land with global measurements ( $\mathrm{CO}$ from MOPITT) and models (for $\mathrm{CH}_{4}$ and $\mathrm{CO}_{2}$ ). We show that elevated concentrations of $\mathrm{CO}$ resulting from biomass burning have been detected in reasonable agreement with MOPITT. The measured $\mathrm{XCH}_{4}$ is enhanced over India, south-east Asia, and central Africa in September/October 2003 in line with model simulations, where they result from surface sources of methane such as rice fields and wetlands. The $\mathrm{CO}_{2}$ measurements over the Northern Hemisphere show the lowest mixing ratios around July in qualitative agreement with model simulations indicating that the large scale pattern of $\mathrm{CO}_{2}$ uptake by the growing vegetation can be detected with SCIAMACHY. We also identified potential problems such as a too low inter-hemispheric gradient for $\mathrm{CO}$, a time dependent bias of the methane columns on the order of a few percent, and a few percent too high $\mathrm{CO}_{2}$ over parts of the Sahara.
\end{abstract}

\section{Introduction}

Knowledge about the global distribution of carbon monoxide (CO) and of the relatively well-mixed greenhouse gases

Correspondence to: $\mathrm{M}$. Buchwitz

(michael.buchwitz@iup.physik.uni-bremen.de) methane $\left(\mathrm{CH}_{4}\right)$ and carbon dioxide $\left(\mathrm{CO}_{2}\right)$ is important for many reasons. $\mathrm{CO}$, for example, plays a central role in tropospheric chemistry (see, e.g., Bergamaschi et al., 2000, and references given therein) as $\mathrm{CO}$ is the leading sink of the hydroxyl radical $(\mathrm{OH})$ which itself largely determines the oxidizing capacity of the troposphere and, therefore, its self-cleansing efficiency and the concentration of greenhouse gases such as $\mathrm{CH}_{4}$. $\mathrm{CO}$ also has large air quality impact as a precurser to tropospheric ozone, a secondary pollutant associated with respiratory problems and decreased crop yields. Satellite measurements of $\mathrm{CH}_{4}, \mathrm{CO}_{2}$, and $\mathrm{CO}$ in combination with inverse modeling have the potential to help better understand their surface sources and sinks than currently possible with the very accurate but rather sparse data from the network of surface stations (see Houweling et al., 1999, 2004; Rayner and O'Brien, 2001, and references given therein). A better understanding of the sources and sinks of $\mathrm{CH}_{4}$ and $\mathrm{CO}_{2}$ is important for example to accurately predict the future concentrations of these gases and associated climate change. Monitoring of the emissions of these gases is also required by the Kyoto protocol.

The first $\mathrm{CO}$ measurements from SCIAMACHY have been presented in Buchwitz et al. (2004), and first results on $\mathrm{CH}_{4}$ and $\mathrm{CO}_{2}$ have been presented in Buchwitz et al. (2005), both papers focusing on a detailed analysis of single day data (except for $\mathrm{CO}_{2}$ for which also time averaged data have been discussed). Here we present the first large data set of the above mentioned gases obtained by processing nearly a year of nadir radiance spectra using initial versions (v0.4 and v0.41) of the WFM-DOAS retrieval algorithm. WFM-DOAS is a scientific retrieval algorithm which is independent of the official operational algorithm of DLR/ESA.

The SCIAMACHY/WFM-DOAS data set has been compared with independent ground based Fourier Transform Spectroscopy (FTS) measurements. These comparisons, which are limited to the data close to a given ground station,

(C) 2005 Author(s). This work is licensed under a Creative Commons License. 
are described elsewhere in this issue (Dils et al., 2005; Sussmann et al., 2005). Initial comparison for a sub-set of the data can be found in de Maziere et al. (2004); Sussmann and Buchwitz (2005); Warneke et al. (2005). The findings of these validation studies are consistent with the findings that will be reported in this study. Here, however, we focus on the comparison with global reference data.

High quality trace gas column retrieval from the SCIAMACHY near-infrared spectra is a challenging task for many reasons, e.g., because of calibration issues mainly related to high and variable dark signals (Gloudemans et al., 2005), because the weak CO lines are difficult to be detected, and because of the challenging accuracy and precision requirements for $\mathrm{CO}_{2}$ (Rayner and O'Brien, 2001; Houweling et al., 2004) and $\mathrm{CH}_{4}$. When developing a retrieval algorithm many decisions have to be made (selection of spectral fitting window, inversion procedure including definition of fit parameters and use of a priori information, radiative transfer approximations, etc.) to process the data in an optimum way such that a good compromise is achieved between processing speed and accuracy of the data products. In this context it is important to point out that other groups are also working on this important topic using quite different approaches (see Gloudemans et al., 2004, 2005; Frankenberg et al., 2005a,b,c; Houweling et al., 2005).

This paper is organized as follows: In Sect. 2 the SCIAMACHY instrument is introduced followed by a description of the WFM-DOAS retrieval algorithm in Sect. 3. Section 4 gives an overview about the processed data mainly in terms of time coverage. The main sections are the three Sects. 5-7 where the results for $\mathrm{CO}, \mathrm{CH}_{4}$, and $\mathrm{CO}_{2}$ are separately presented and discussed. The conclusions are given in Sect. 8 and a short summary of our latest developments (v0.5 CO and $\mathrm{XCH}_{4}$ ) is given in Sect. 9.

\section{The SCIAMACHY instrument}

The SCanning Imaging Absorption spectroMeter for Atmospheric CHartographY (SCIAMACHY) instrument (Burrows et al., 1995; Bovensmann et al., 1999, 2004) is part of the atmospheric chemistry payload of the European Space Agencies (ESA) environmental satellite ENVISAT, launched in March 2002. ENVISAT flies in sun-synchronous polar low Earth orbit crossing the equator at 10:00 AM local time. SCIAMACHY is a grating spectrometer that measures spectra of scattered, reflected, and transmitted solar radiation in the spectral region 240-2400 nm in nadir, limb, and solar and lunar occultation viewing modes.

SCIAMACHY consists of eight main spectral channels (each equipped with a linear detector array with 1024 detector pixels) and seven spectrally broad band Polarization Measurement Devices (PMDs) (details are given in Bovensmann et al., 1999). For this study observations of channel 6 (for $\mathrm{CO}_{2}$ ) and 8 (for $\mathrm{CH}_{4}, \mathrm{CO}$, and $\mathrm{N}_{2} \mathrm{O}$ ), and Polarization
Measurement Device (PMD) number $1(\sim 320-380 \mathrm{~nm})$ have been used. In addition, channel 4 has been used to determine the mass of dry air from oxygen $\left(\mathrm{O}_{2}\right)$ column measurements using the $\mathrm{O}_{2} \mathrm{~A}$ band. Channels 4, 6 and 8 measure simultaneously the spectral regions $600-800 \mathrm{~nm}, 970-1772 \mathrm{~nm}$ and $2360-2385 \mathrm{~nm}$ at spectral resolutions of $0.4,1.4$ and $0.2 \mathrm{~nm}$, respectively. For SCIAMACHY the spatial resolution, i.e., the footprint size of a single nadir measurement, depends on the spectral interval and orbital position. For channel 8 data the spatial resolution is $30 \times 120 \mathrm{~km}^{2}$ corresponding to an integration time of $0.5 \mathrm{~s}$, except at high solar zenith angles (e.g., polar regions in summer hemisphere), where the pixel size is twice as large $\left(30 \times 240 \mathrm{~km}^{2}\right)$. For the channel 4 and 6 data used for this study the integration time is mostly $0.25 \mathrm{~s}$ corresponding to a horizontal resolution of $30 \times 60 \mathrm{~km}^{2}$. SCIAMACHY also performs direct (extraterrestrial) sun observations, e.g., to obtain the solar reference spectra needed for the retrieval.

SCIAMACHY is one of the first instruments that performs nadir observations in the near-infrared (NIR) spectral region (i.e., around $2 \mu \mathrm{m}$ ). In contrast to the ultra violet (UV) and visible spectral regions where high performance $\mathrm{Si}$ detectors have been manufactured for a long time, no appropriate near-infrared detectors were available when SCIAMACHY was designed. The near-infrared InGaAs detectors of SCIAMACHY were a special development for SCIAMACHY. Compared to the UV-visible detectors they are characterized by a substantially higher pixel-to-pixel variability of the quantum efficiency and the dark (leakage) current. Each detector array has a large number of dead and bad pixels. In addition, the dark signal is significantly higher compared to the UV-visible mainly because of thermal radiation generated by the instrument itself. The in-flight optical performance of SCIAMACHY is overall as expected from the onground calibration and characterization activities (Bovensmann et al., 2004). One exception is the time dependent optical throughput variation in the SCIAMACHY NIR channels 7 and 8 due the build-up of an ice layer on the detectors ("ice issue") (Gloudemans et al., 2005). This effect is minimized by regular heating of the instrument (Bovensmann et al., 2004) during decontamination phases. The ice layers adversely influence the quality of the retrieval of all gases discussed in this paper as they result in reduced throughput (transmission) and, therefore, reduced signal and signal-tonoise performance. In addition, changes of the instrument slit function have been observed which introduce systematic errors (Gloudemans et al., 2005). All these issues complicate the retrieval.

\section{WFM-DOAS retrieval algorithm}

The Weighting Function Modified Differential Optical Absorption Spectroscopy (WFM-DOAS) retrieval algorithm and its current implementation is described in detail 

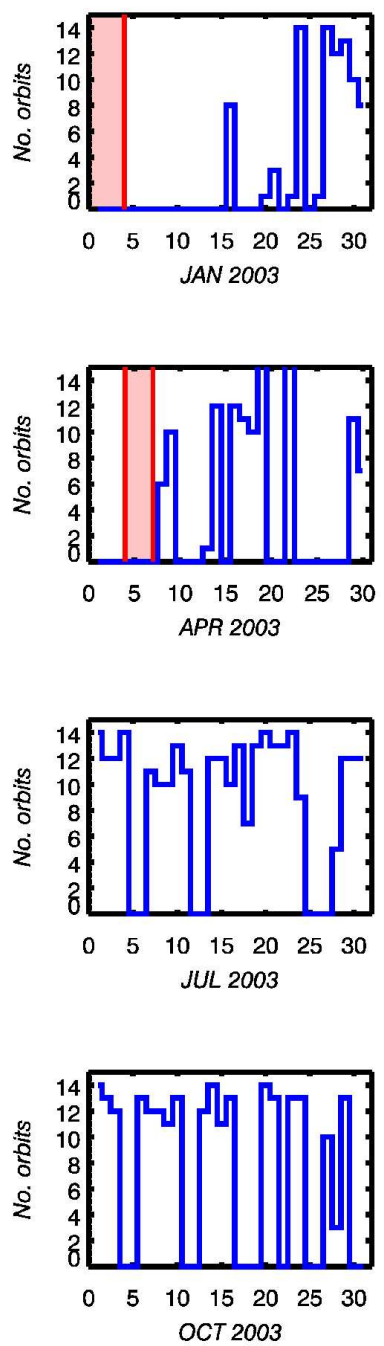
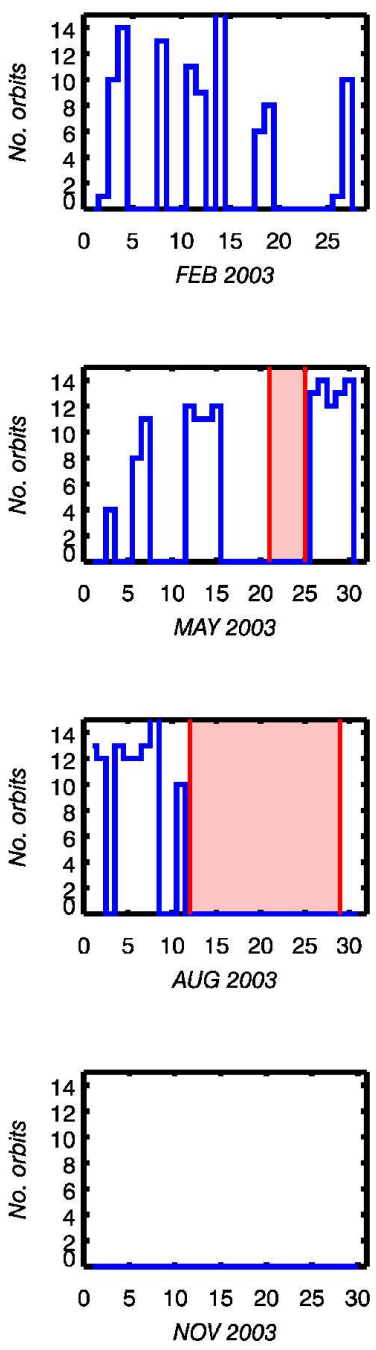
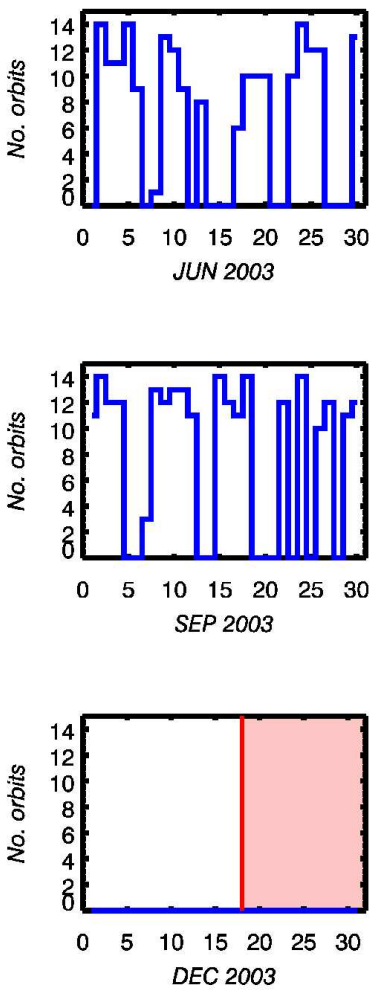

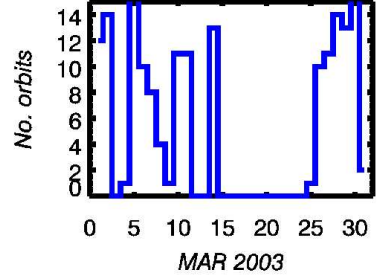

Fig. 1. Number of orbits per day of the year 2003 processed by WFM-DOAS (blue lines). The maximum number of orbits per day is about $14(\sim 100 \%)$. The red shaded areas indicate the decontamination phases performed to get rid of the ice layer that grows on the near-infrared detectors of channels 7 and 8. Data gaps are due to decontamination but also due to other (mostly ground processing related) reasons.

elsewhere (Buchwitz et al., 2000a, 2004, 2005). In short, WFM-DOAS is an unconstrained linear-least squares method based on scaling pre-selected trace gas vertical profiles. The fit parameters are the desired vertical columns. The logarithm of a linearized radiative transfer model plus a loworder polynomial is fitted to the logarithm of the ratio of the measured nadir radiance and solar irradiance spectrum, i.e., observed sun-normalized radiance. The WFM-DOAS reference spectra are the logarithm of the sun-normalized radiance and its derivatives. They are computed with a radiative transfer model taking into account line-absorption and multiple scattering (Buchwitz et al., 2000b). A fast look-up table scheme has been developed in order to avoid time consuming on-line radiative transfer simulations. A detailed description of the look-up table is given in Buchwitz and Burrows (2004) (please note that the current version of the look-up table is based on HITRAN2000/2003 line parameters) (Rothmann et al., 2003). A short description is also provided in Buchwitz et al. (2005).

In order to identify cloud-contaminated ground pixels we use a simple threshold algorithm based on sub-pixel information as provided by the SCIAMACHY Polarization Measurement Devices (PMDs) (details are given in Buchwitz et al., 2004, 2005). We use PMD1 which corresponds to the spectral region $320-380 \mathrm{~nm}$ located in the UV part of the spectrum. Strictly speaking, the algorithm detects enhanced backscatter in the UV. Enhanced UV backscatter mainly results from clouds but might also be due to high aerosol loading or high surface UV spectral reflectance. As a result, ice or snow covered surfaces may be wrongly classified as cloud contaminated. This needs to be improved in future versions of our retrieval method. 
The quality of the WFM-DOAS fits in the near-infrared is poor (i.e., the fit residuals are large) when applying WFMDOAS to the operational Level 1 data products. In order to improve the quality of the fits and thereby the quality of our data products we pre-process the operational Level 1 data products mainly with respect to a better dark signal calibration (see Buchwitz et al., 2004, 2005). In addition, there are indications that the in-orbit slit function of SCIAMACHY is different from the one measured on-ground (Gloudemans et al., 2005) due to the ice layer (see Sect. 2). We use a slit function that has been determined by applying WFM-DOAS to the in-orbit nadir measurements. We selected the one that resulted in best fits, i.e., smallest fit residuum (see Buchwitz et al., 2004, 2005).

\section{WFM-DOAS data products: Time coverage}

The WFM-DOAS trace gas column data products have been derived by processing all consolidated SCIAMACHY Level 1 operational product files (i.e., the calibrated and geolocated spectra) of the year 2003 that have been made available by ESA/DLR (up to mid-2004). Figure 1 gives an overview about the number of orbits per day that have been processed. The maximum number of orbits per day is about fourteen. As can been seen (blue lines), all 14 orbits were available for only a small number of days. For many days no data were available. Many of the large data gaps are due to decontamination phases (see Sect. 2) which are indicated by red shaded areas. For November and December 2003 no consolidated (i.e., full product) orbit files have been made available (for ground processing related reasons).

\section{Carbon monoxide (CO)}

CO columns have been retrieved from a small spectral fitting window $(2359-2370 \mathrm{~nm})$ located in SCIAMACHY channel 8. The fitting window covers four $\mathrm{CO}$ absorption lines. The retrieval is complicated by strong overlapping absorption features of methane and water vapor. The first $\mathrm{CO}$ results from SCIAMACHY have been presented in Buchwitz et al. (2004) focusing on a detailed analysis of three days of data of the year 2003. For details concerning pre-processing of the spectra (for improving the calibration), WFM-DOAS v0.4 retrieval, vertical column averaging kernels, quality of the spectral fits, and a quantitative comparison with MOPITT Version 3 CO columns (Deeter et al., 2003; Emmons et al., 2004) we refer to Buchwitz et al. (2004). An initial error analysis using simulated measurements can be found in Buchwitz et al. (2004) and Buchwitz and Burrows (2004) where it is shown that the retrieval errors are expected to be less than about 20\%. In Buchwitz et al. (2004) it has been shown that plumes of elevated $\mathrm{CO}$ can be detected with single overpass data in good qualitative agreement with
MOPITT. Globally, for measurements over land, the standard deviation of the difference with respect to MOPITT was shown to be in the range $0.4-0.6 \times 10^{18}$ molecules $/ \mathrm{cm}^{2}$ and the linear correlation coefficient between 0.4 and 0.7 . The differences of the $\mathrm{CO}$ from the two sensors depend on time and location but are typically within 30\% for most latitudes. Perfect agreement with MOPITT is, however, not to be expected for a number of reasons (differences in overpass time, spatial resolution, etc.). In this context it is important to point out that the sensitivity of SCIAMACHY measurements is nearly independent of altitude whereas the sensitivity of MOPITT to boundary layer $\mathrm{CO}$ is low. On the other hand, retrieval of CO from SCIAMACHY is not unproblematic. For example, the WFM-DOAS v0.4 CO columns are scaled with a constant factor of 0.5 to compensate for an obvious overestimation (see Buchwitz et al., 2004, for details). This overestimation is most probably closely related to the difficulty of accurately fitting the weak $\mathrm{CO}$ lines in the selected fitting window (note that the CO columns of our new version 0.5 data product, which is retrieved from a different fitting window, are not scaled any more; see Sect. 9 for details). The fit residuals, which are on the order of the $\mathrm{CO}$ lines, are not signal-to-noise limited but dominated by (not yet understood) rather stable spectral artifacts.

Figure 2 shows a comparison of tri-monthly averaged WFM-DOAS version $0.4 \mathrm{CO}$ columns with $\mathrm{CO}$ from MOPITT (version 3). Because of the low surface reflectivity of water in the NIR (outside sun-glint conditions) the nadir measurements are noisy over the ocean. Therefore, we focus on SCIAMACHY measurements over land. Only these measurements are shown in Fig. 2. The same land mask as used for SCIAMACHY has also been used for MOPITT to ease the comparison. SCIAMACHY data have only been included in Fig. 2 if the CO fit error was less than $60 \%$ and when the pixels were cloud free. As can be seen from Fig. 1, there are large SCIAMACHY data gaps. Therefore, the SCIAMACHY data shown in Fig. 2 are not tri-monthly averages obtained from a bias free sampling. For example, the JulySeptember average is strongly weighted towards July and September due to a long decontamination period with no data in August. There are also gaps in the tropical region due to persistent cloud cover. Furthermore, there are no data over Greenland and Antarctica, and over large parts of the Northern Hemisphere in the period January to March. This is partially also due to clouds but mainly due to ice/snow covered surfaces because of the limitations of the cloud detection algorithm.

When comparing the January-March data from SCIAMACHY and MOPITT one can see that there are similarities but also differences. For example, the inter-hemispheric difference is clearly visible for MOPITT but barely visible for SCIAMACHY. Both sensors see low columns over regions of elevated surface topography (Himalaya, Andes and Rocky Mountains) and high columns over the western part of central Africa (where significant biomass burning is going 

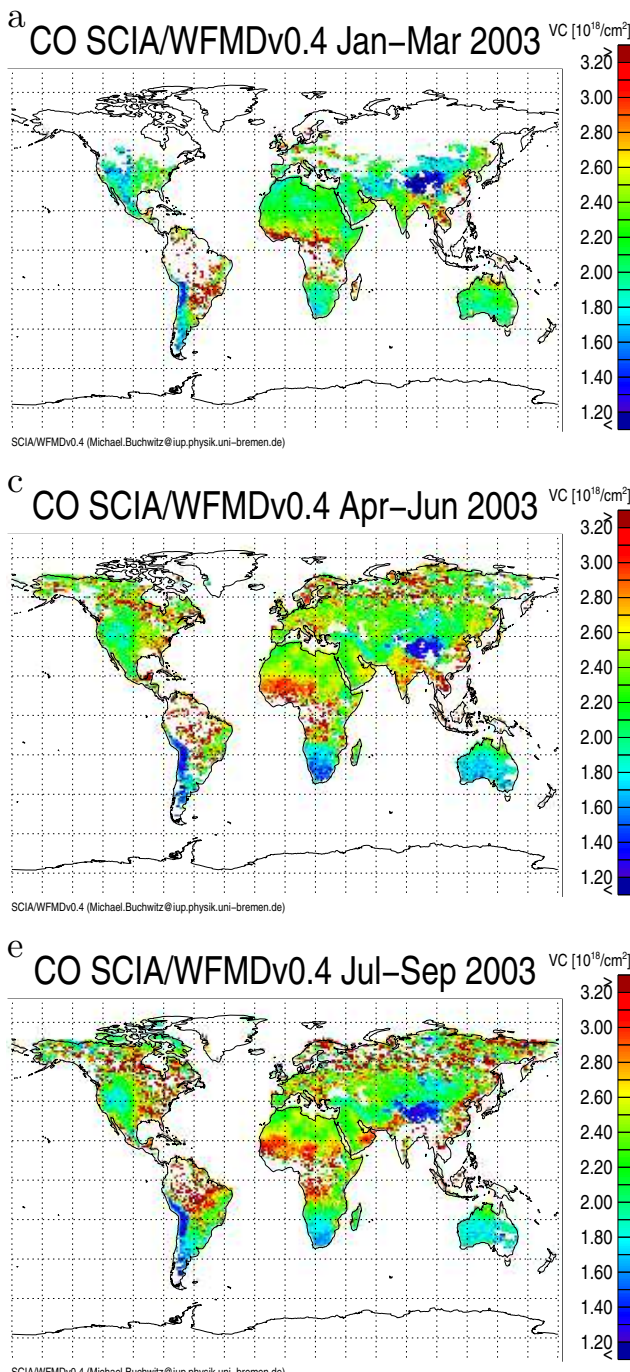
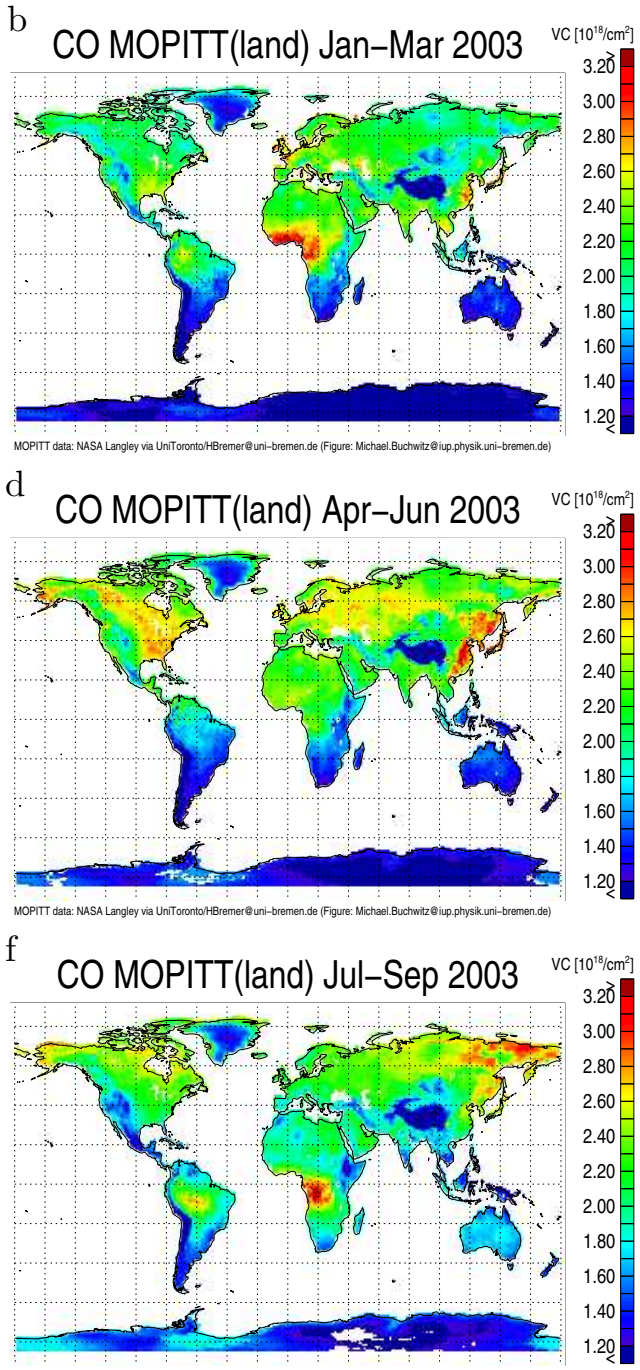

Fig. 2. Tri-monthly averaged CO columns over land from SCIAMACHY/ENVISAT (left) and MOPITT/EOS-Terra (right). Only the columns over land are shown because the quality of the SCIAMACHY CO columns over water is low due to the low reflectivity of water in the nearinfrared. For SCIAMACHY only data have been averaged where the CO fit error is less than $60 \%$ and where the PMD1 cloud identification algorithm indicates a cloud free pixel. For MOPITT cloudy pixels are also not included.

on during the dry season), south-east Asia, parts of Europe, and the south-eastern part of the United States of America. Over South America and the northern part of Australia SCIAMACHY sees elevated CO not observed by MOPITT.

During April to June both sensors see elevated CO over large parts of the Northern Hemisphere (eastern part of the US, Canada, western Europe and large parts of Russia (the observed pattern are, however, not exactly identical), southeast Asia and parts of China. Over India and parts of south-east Asia SCIAMACHY sees elevated CO not seen by MOPITT. The largest difference over the Northern Hemisphere occurs over the western part of central Africa where the CO retrieved from SCIAMACHY is significantly higher than the $\mathrm{CO}$ from MOPITT. The reason for the elevated
SCIAMACHY CO columns over the Sahel region is not yet exactly understood but it is very likely that this is an overestimation due to systematic artifacts (caused by, for example, aerosol). This is supported by the fact that our new version 0.5 CO WFM-DOAS data product, which is shortly described in Sect. 9, shows significantly lower values over this region compared to v0.4. The version $0.5 \mathrm{CO}$ columns are less sensitive to errors related to average light path (or observed airmass) uncertainty resulting from the unknown distribution of scattering material (aerosols, clouds) in the atmosphere and/or surface reflectivity variability. The reason for this is that the $\mathrm{CO} 0.5$ column is normalized by the methane column obtained from the same spectral fitting window resulting in (at least partial) canceling of errors. Also over large 
SCIA/WFMDv0.4/XCH4 vs Ch8/Transmission

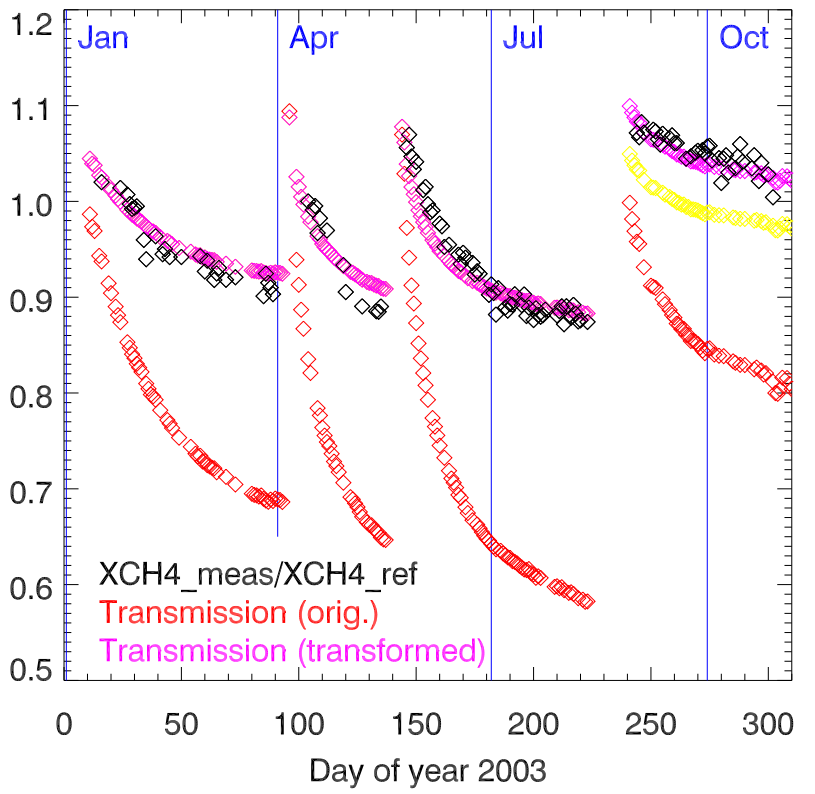

Fig. 3. The black diamonds show $\mathrm{XCH}_{4}$ (v0.4) as measured by SCIAMACHY over the Sahara normalized by a constant reference value of $1750 \mathrm{ppbv}$ as a function of day of the year 2003 ("methane bias curve"). The red diamonds ("Transmission (orig.)") show independent measurements, namely the SCIAMACHY channel 8 transmission which changes due to the varying ice layer on the detector. This curve has been determined by averaging the signal of the solar measurements and normalizing it. The magenta $(\mathrm{m})$ "Transmission (transformed)" curve has been obtained by a linear transformation of the red $(r)$ curve, i.e., by computing $m=A+B r$. Applying the same coefficients A and B as used for the data before day 230 also to the data after day 230 results in the yellow curve which still shows an offset with respect to the black methane bias curve. To get a better match, two sets of coefficients have been used, one for the data before day 230 and another set for the data after day 230. The reason why different coefficients are needed is most probably because the spatial distribution of the ice layer on the detector changes with time.

parts of South America the SCIAMACHY measurements are significantly higher than MOPITT (WFM-DOAS version 0.5 also shows higher values than MOPITT confirming the v0.4 results). For the time period July to September the pattern of elevated $\mathrm{CO}$ as observed by SCIAMACHY is similar to the SCIAMACHY observations during April to June. The main differences are: (i) higher values over Southern America (in quantitative agreement with MOPITT; note that this is the time where most of the biomass burning takes place in this area) and (ii) higher values over the eastern part of northern Russia (also observed by MOPITT). There are also significant differences when comparing the SCIAMACHY data with MOPITT especially over the northern part of central Africa, the eastern US, south-east Asia and over most of the mid to high latitude parts of the Northern Hemisphere.
In summary, the agreement with MOPITT is reasonable but there are large differences at certain locations during certain times of the year. More investigations are needed to explain the observed differences taking into account the different altitude sensitivities of both sensors.

\section{Methane $\left(\mathrm{CH}_{4}\right)$}

The methane columns have been retrieved from a small spectral fitting window $(2265-2280 \mathrm{~nm})$ located in SCIAMACHY channel 8 which covers several absorption lines of $\mathrm{CH}_{4}$ and several (much weaker) absorption lines of nitrous oxide $\left(\mathrm{N}_{2} \mathrm{O}\right)$ and water vapor $\left(\mathrm{H}_{2} \mathrm{O}\right)$. The main scientific application of the methane measurements of SCIAMACHY is to obtain information on the surface sources of methane. The modulation of methane columns due to methane sources is only on the order of a few percent. This is much weaker than the variation of the methane column due to changes of surface pressure/surface elevation (because methane is well-mixed the methane column is highly correlated with the total air mass over a given location and, therefore, with surface pressure). To filter out these much larger disturbing modulations, the methane columns need to be normalized by the observed airmass to obtain a so called dry air column averaged mixing ratio of methane (denoted $\left.\mathrm{XCH}_{4}\right)$. To accomplish this, oxygen $\left(\mathrm{O}_{2}\right)$ columns have been retrieved in addition to the methane columns. From the oxygen columns the airmass can be calculated using its constant mixing ratio of 0.2095 . The $\mathrm{O}_{2}$ columns used to compute the WFM-DOAS v0.4 $\mathrm{XCH}_{4}$ data product have been retrieved from the SCIAMACHY measurements in the $\mathrm{O}_{2} \mathrm{~A}$ band spectral region (around $760 \mathrm{~nm}$; channel 4).

First $\mathrm{CH}_{4}$ results from SCIAMACHY have been presented in Buchwitz et al. (2005) focusing on a detailed analysis of four days of data of the year 2003. For details concerning pre-processing of the spectra (to improve the calibration), WFM-DOAS (v0.4) processing, averaging kernels, quality of the spectral fits, an initial error analysis (see also Buchwitz and Burrows, 2004), and a quantitative comparison with global models we refer to that study. According to the error analysis errors of a few percent due to undetected cirrus clouds, aerosols, surface reflectivity, temperature and pressure profiles, etc., are to be expected. It has been shown in Buchwitz et al. (2005) that the WFM-DOAS Version 0.4 methane columns have a time dependent (nearly globally uniform) bias of up to $-15 \%$ (low bias of SCIAMACHY) for one of the four days that have been analyzed. The bias is correlated with the time after the last decontamination performed to get rid of the ice layers on the detector. Therefore, Buchwitz et al. (2005) concluded that the bias might be due to the "ice-issue" (see Sect. 2). This is consistent with the finding of Gloudemans et al. (2005) that the ice build-up on the detectors results in a broadening of the instrument slit function (the wider the slit function compared to the assumed 

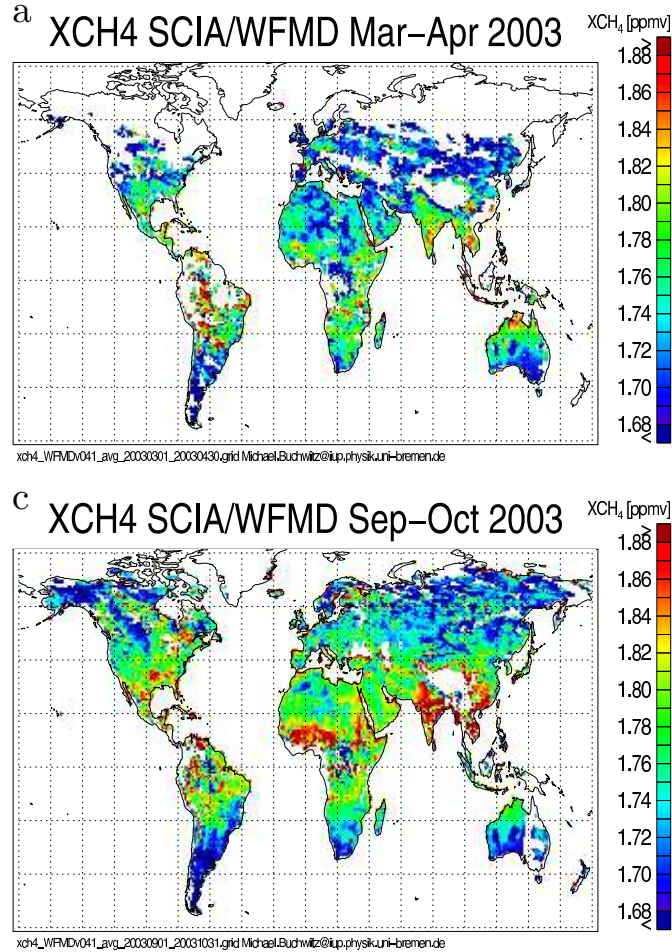

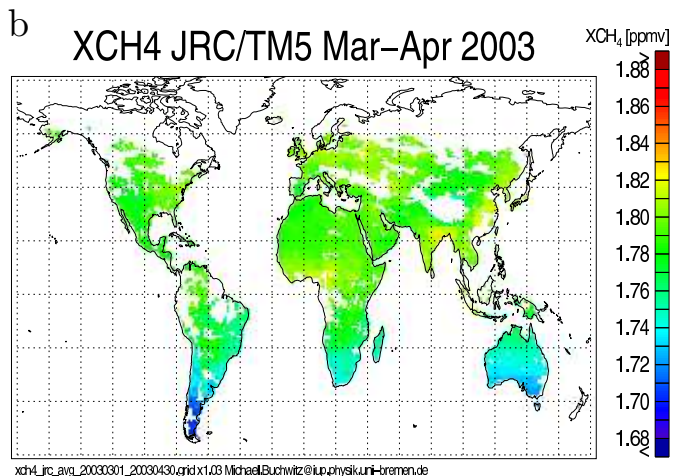

d

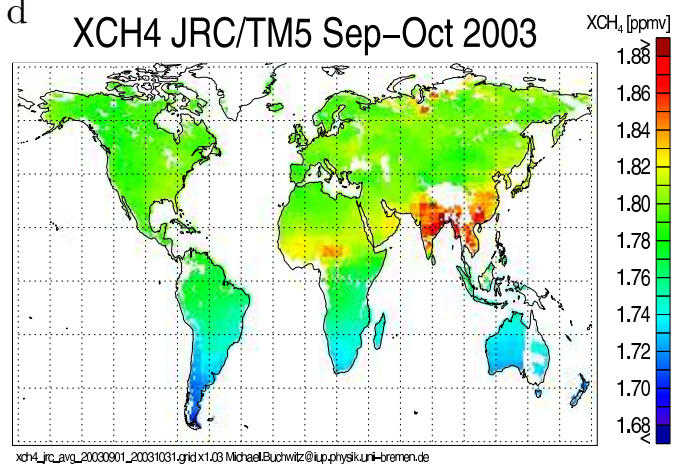

Fig. 4. Column averaged mixing ratios of methane $\left(\mathrm{XCH}_{4}\right)$ as measured by SCIAMACHY over land using WFM-DOAS v0.41 (left) compared to TM5 model data (right). For SCIAMACHY only the measurements from cloud free pixels have been averaged where the methane error is less than $10 \%$. The model data have been averaged taking into account the daily sampling of the SCIAMACHY data. The model data have been scaled by a constant factor of 1.03 to compensate for the bias between the two data sets (see Fig. 5).

slit function, the larger the underestimation of the retrieved methane column).

Typically, the weak methane source signal is difficult to be clearly detected with single overpass or single day SCIAMACHY data. For accurate detection of methane sources averages have to be computed. Because of the time dependent bias of the WFM-DOAS v0.4 methane columns this is, however, not directly possible.

In the following we describe how we have processed the SCIAMACHY data to get an improved version of our methane data product (Version 0.41 ) by applying a bias correction to the v0.4 methane columns. We assume that the data can be sufficiently corrected by dividing the columns by a globally constant scaling factor which only depends on time (on the day of the measurement). The correction factor has been determined as follows: For each day all cloud free v0.4 $\mathrm{XCH}_{4}$ measurements over the Sahara have been averaged. The ratio of these daily average mixing ratios to a constant reference value (chosen to be $1750 \mathrm{ppbv}$ ) is approximately the methane bias (because methane is not constant this is not exactly the methane bias and a certain systematic error is introduced by this assumption). This time dependent methane bias is shown in Fig. 3 (black diamonds). This bias shows a similar time dependence as the independently measured channel 8 transmission loss also shown in Fig. 3 (red diamonds). The transmission has been determined by averaging the signal of the channel 8 solar measurements normalized to a reference measurement at the beginning of the mission. The varying transmission is a consequence of the varying ice layer on the detectors. Figure 3 shows a third curve, the (daily) correction factor (magenta diamonds). The correction factor curve has been obtained by linearly transforming the transmission curve. The coefficients of the linear transformation have been selected such that a good match is obtained with the methane bias curve. In order to correct the WFM-DOAS v0.4 methane columns for the systematic errors introduced by the ice layer the correction factors are applied as follows: All v0.4 methane columns of a given day have been divided by the correction factor for this day. The corrected WFM-DOAS v0.4 methane columns are the new WFM-DOAS v0.41 (absolute) methane columns.

In order to generate the new WFM-DOAS v0.41 $\mathrm{XCH}_{4}$ product a second modification has been applied: Instead of normalizing the methane columns by the oxygen column retrieved from the $760 \mathrm{~nm} \mathrm{O}_{2} \mathrm{~A}$ band (as done for $\mathrm{v} 0.4 \mathrm{XCH}_{4}$ ), they have been normalized by the $\mathrm{CO}_{2}$ columns retrieved from the $1580 \mathrm{~nm}$ region (for details on $\mathrm{CO}_{2}$ retrieval see Sect. 7). Using $\mathrm{CO}_{2}$ rather than $\mathrm{O}_{2}$ for normalizing the 
methane columns has been first proposed by Frankenberg et al. (2005c) (the approach has been presented earlier, namely at the ENVISAT Symposium, Salzburg, Austria, September 2004).

The reason why normalizing methane by $\mathrm{CO}_{2}$ rather than $\mathrm{O}_{2}$ is expected to give better results for $\mathrm{XCH}_{4}$ is that the $\mathrm{CO}_{2}$ band is located spectrally much closer to the $\mathrm{CH}_{4}$ band than the $\mathrm{O}_{2} \mathrm{~A}$ band. Retrieval errors due to aerosols, residual cloud contamination, surface reflectivity uncertainties, etc., are expected to be the more similar, the more similar the radiative transfer is (including all parameters that influence the radiative transfer such as surface albedo). In general, this requires that the two spectral intervals from which the two columns are retrieved are spectrally located as close as possible next to each other (there are exceptions, of course, for example in case of spectral absorption features). As the $\mathrm{CO}_{2}$ fitting window (at $1580 \mathrm{~nm}$ ), is much closer to the $\mathrm{CH}_{4}$ fitting window $(2270 \mathrm{~nm})$ than the $\mathrm{O}_{2}$ window $(760 \mathrm{~nm})$ canceling of errors will be better using $\mathrm{CO}_{2}$. In addition, when the column retrieval from the two spectral regions suffers from similar instrumental/calibration errors, also these errors cancel to a certain extent (note that in Sect. 9 we shortly describe our latest $\mathrm{XCH}_{4}$ data product (v0.5) derived using methane columns retrieved from channel 6 , i.e., located close to the $\mathrm{CO}_{2}$ fitting window (also channel 6) to improve the cancelling of errors Frankenberg et al., 2005c).

The drawback of this approach is that $\mathrm{CO}_{2}$ is not as constant as $\mathrm{O}_{2}$ mainly because of the surface sources and sinks of $\mathrm{CO}_{2}$. This approach requires that the variability of the column averaged mixing ratio of $\mathrm{CO}_{2}$ is small (ideally negligible) compared to the variability of the column averaged mixing ratio of $\mathrm{CH}_{4}$. According to global model simulation this is a reasonable assumption. The model simulations shown in Buchwitz et al. (2005) indicate that the variability of the methane column is about $6 \%( \pm 100 \mathrm{ppbv})$ and the variability of the $\mathrm{CO}_{2}$ column is about $1.5 \%$ ( \pm 5 ppmv), i.e., a factor of four smaller than for methane. This means that the error introduced by essentially assuming that $\mathrm{CO}_{2}$ is constant is less than about $1.5 \%$. This is comparable to the estimated error on the WFM-DOAS v0.4 $\mathrm{CO}_{2}$ columns as reported in Buchwitz et al. (2005). It has to be pointed out, however, that this aspects needs more study as, for example, the $\mathrm{XCO}_{2}$ results from SCIAMACHY presented in Sect. 7 show a significantly higher $\mathrm{XCO}_{2}$ variability compared to model simulations.

Figure 4 shows a comparison of WFM-DOAS v0.41 $\mathrm{XCH}_{4}$ with TM5 model simulations. The TM5 model is a two-way nested atmospheric zoom model (Krol et al., 2005). It allows to define zoom regions (e.g. over Europe) which are run at higher spatial resolution $(1 \times 1 \mathrm{deg})$, embedded into the global domain, run at a resolution of $6 \times 4 \mathrm{deg}$. We employ the tropospheric standard version of TM5 with 25 vertical layers. TM5 is an off-line model and uses analyzed meteorological fields from the ECMWF weather forecast model to describe advection and vertical mixing by cumulus convection and turbulent diffusion. $\mathrm{CH}_{4}$ (a priori) emissions are as described by Bergamaschi et al. (2005). Chemical destruction of $\mathrm{CH}_{4}$ by $\mathrm{OH}$ radicals is simulated using pre-calculated $\mathrm{OH}$ fields based on CBM-4 chemistry and optimized with methyl chloroform. For the stratosphere also the reaction of $\mathrm{CH}_{4}$ with $\mathrm{Cl}$ and $\mathrm{O}\left({ }^{1} \mathrm{D}\right)$ radicals are considered. The comparison is limited to observations over land as the SCIAMACHY observations over ocean are less precise because of the low ocean reflectivity in the near-infrared. For SCIAMACHY all measurements from cloud free pixels have been averaged where the $\mathrm{CH}_{4}$ column fit error is less than $10 \%$. The bimonthly averages have been computed from daily gridded data. For the model simulations only those grid boxes where measurements were available have been used to compute the averages.

The comparison with the model simulations shows similarities but also differences. Very interestingly and in qualitative agreement with the model simulations, the measurements show high $\mathrm{CH}_{4}$ mixing ratios in the September to October 2003 average over India, southeast Asia, and over the western part of central Africa, which are absent or significantly lower in the March to April average. In the model the high columns over these regions are a result of methane emissions mainly from rice fields, wetlands, ruminants, and waste handling. The good agreement with the model simulations indicates that SCIAMACHY can detect these emission signals. Similar findings have been reported in Frankenberg et al. (2005c). However, there are also differences compared to the model simulations. For example, in the March-April average the SCIAMACHY data are a few percent higher over large parts of northern South America. Over large parts of the Northern Hemisphere the SCIAMACHY data are a few percent lower.

We have also compared monthly averaged v0.41 $\mathrm{XCH}_{4}$ with (the throughput-based) bias corrected $\mathrm{v} 0.4 \mathrm{XCH}_{4}$ to assess the impact of normalizing by $\mathrm{CO}_{2}$ (as done for v0.41) compared to normalizing by $\mathrm{O}_{2}$ (as done for v0.4). For example for October 2003 this comparison showed significant differences. The extended plumes of high v0.41 $\mathrm{XCH}_{4}$ over India, China, and central Africa (similar as those shown in Fig. 4) do not show up so clearly in the v0.4 $\mathrm{XCH}_{4}$. In addition, there are also large differences at other places with the v0.4 $\mathrm{XCH}_{4}$ being more "noisy" (more inhomogeneous) than $\mathrm{V} 0.41 \mathrm{XCH}_{4}$. This confirms that cancellation of errors is better for $\mathrm{v} 0.41 \mathrm{XCH}_{4}$ (normalization by $\mathrm{CO}_{2}$ ) than for $\mathrm{v} 0.4 \mathrm{XCH}_{4}$ (normalization by $\mathrm{O}_{2}$ ). The impact of using the $\mathrm{O}_{2}$ measurements to obtain column averaged mixing ratios is further discussed in Sect. 7 where it has been used to obtain $\mathrm{XCO}_{2}$.

Figure 5 shows a quantitative comparison of the global daily data with the TM5 model, the correlation coefficient and the bias for the two versions of SCIAMACHY $\mathrm{XCH}_{4}$ data products, namely v0.4 and v0.41. As can be seen, the bias is significantly smaller for the v0.41 data, although not zero. There still appears to be a systematic bias due to the ice issue indicating that the bias correction applied to generate 

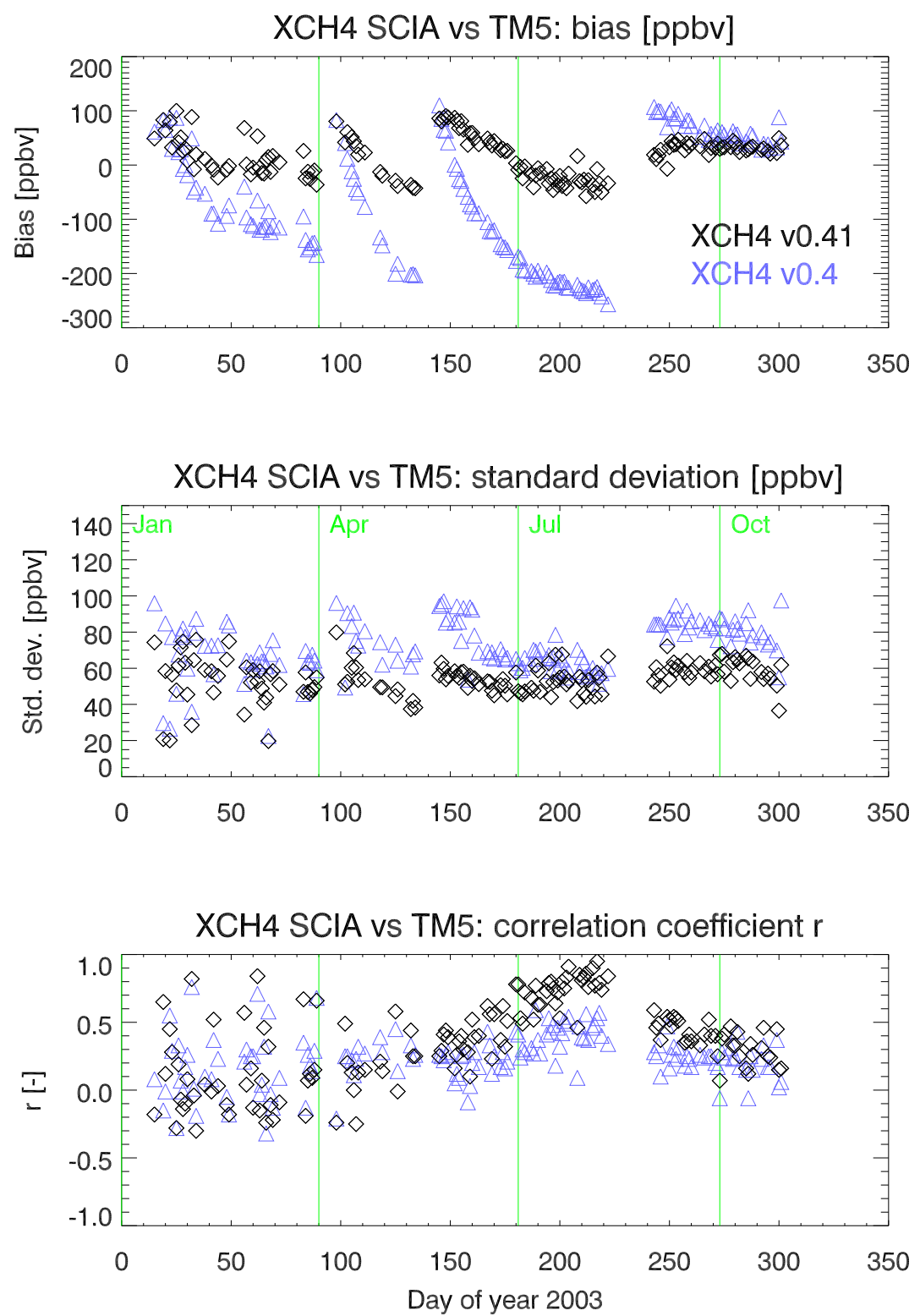

Fig. 5. Comparison of daily SCIAMACHY $\mathrm{XCH}_{4}$ measurements (versions 0.4 (blue triangles) and 0.41 (black diamonds)) with TM5 model simulations. The top panel shows the bias (SCIAMACHY-model), the middle panel the standard deviation of the difference, and the bottom panel Pearson's linear correlation coefficient $r$.

the v0.41 data is not perfect. Also the correlation with the model results is typically significantly better for the version 0.41 data.

\section{Carbon dioxide $\left(\mathrm{CO}_{2}\right)$}

The $\mathrm{CO}_{2}$ columns have been retrieved using a small spectral fitting window (1558-1594 nm) located in SCIAMACHY channel 6 (which is not affected by an ice layer). This spectral region covers one absorption band of $\mathrm{CO}_{2}$ and weak absorption features of water vapor. As for methane v0.4 (air or)
$\mathrm{O}_{2}$-normalized $\mathrm{CO}_{2}$ columns have been derived, the dry air column averaged mixing ratios $\mathrm{XCO}_{2}$. First results of $\mathrm{CO}_{2}$ from SCIAMACHY have been presented in Buchwitz et al. (2005). For details concerning pre-processing of the spectra (for improving the calibration), WFM-DOAS (v0.4) processing, vertical column averaging kernels, quality of the spectral fits, and a quantitative comparison with global model simulations we refer to Buchwitz et al. (2005). An initial error analysis using simulated measurements is given in Buchwitz et al. (2005) and Buchwitz and Burrows (2004). According to this analysis, errors of a few percent due to undetected 
cirrus clouds, aerosols, surface reflectivity, temperature and pressure profiles, etc., are to be expected. To compensate for a not yet understood systematic underestimation of the initially retrieved $\mathrm{CO}_{2}$ columns the WFM-DOAS v0.4 $\mathrm{CO}_{2}$ columns have been scaled with a constant factor of 1.27 (see Buchwitz et al., 2005, for details). The factor has been chosen to make sure that the $\mathrm{CO}_{2}$ column is near its expected value of about $8 \times 10^{21}$ molecules $/ \mathrm{cm}^{2}$ for a cloud free scene with a surface elevation close to sea level and moderate surface albedo. In Buchwitz et al. (2005) it has been shown that the WFM-DOAS v0.4 $\mathrm{CO}_{2}$ (scaled) columns agree with model columns within a few percent (range $-3.7 \%$ to $+2.0 \%$ ). Because of the scaling factor a meaningful comparison with reference data should focus on variability in time and space and not on the absolute level. Also the v0.4 $\mathrm{O}_{2}$ columns, used to compute $\mathrm{XCO}_{2}$, are scaled (by 0.85 ). The reason for the about $15 \%$ overestimation of the originally retrieved $\mathrm{O}_{2}$ columns is currently unclear. The factor has been chosen to make sure that the $\mathrm{O}_{2}$ column is near its expected value of about $4.5 \times 10^{24}$ molecules $/ \mathrm{cm}^{2}$ for a cloud free scene with a surface elevation close to sea level and moderate surface albedo. In a recent paper of van Diedenhofen et al. (2005) an overestimation of $2-5 \%$ over scenes with moderate to high surface albedo is found when comparing their SCIAMACHY $\mathrm{O}_{2}$ columns with actual meteorological data. They found that $2 \%$ can be explained by an offset on the measured reflectance and argue that the remaining overestimation is likely due to aerosols. Taking this into account our retrievals are still overestimated by $10 \%$. At present we cannot offer an explanations for this discrepancy. The investigation of this will be a focus of our future work. For now we have to state that the v0.4 $\mathrm{CO}_{2}$ and $\mathrm{O}_{2}$ columns are scaled resulting in a quite large scaling factor for $\mathrm{XCO}_{2}$ of $1.49(=1.27 / 0.85)$. Because of this we focus on variability rather than on absolute $\mathrm{XCO}_{2}$ levels when comparing our $\mathrm{XCO}_{2}$ to reference data.

In Buchwitz et al. (2005) it has been shown that the spatial and temporal pattern of the retrieved column averaged mixing ratio is in reasonable agreement with the model data except for the amplitude of the variability. The measured variability is about a factor of four higher than the variability of the model data (about 6\% compared to about $1.5 \%$ for the model data). This is also confirmed in this study which provides more details on this finding. In this context it is important to note that an overestimation of the retrieved variability of about a factor 2.2 (at maximum) may be explained as follows: The SCIAMACHY/WFM-DOAS $\mathrm{CO}_{2}$ column averaging kernels (shown in Buchwitz et al., 2005) peak in the lower troposphere and have a maximum value of about 1.5 . This means that the retrieved variability is overestimated by $50 \%$ (e.g., 3 ppmv instead of 2 ppmv) if this column variability is entirely due to variability in the lower troposphere (note that the averaging kernels typically decrease with altitude and reach 1.0 (i.e., no over- or underestimation) around $400 \mathrm{hPa}(\sim 7 \mathrm{~km})$; above $400 \mathrm{hPa}$ they are less than 1.0). The scaling factor of 1.49 which is currently applied to the retrieved $\mathrm{XCO}_{2}$ may also contribute to an enhancement of the retrieved variability. This however requires that the initially retrieved columns are off by a constant offset rather than a constant scaling factor (this aspect needs further investigation). The averaging kernels in combination with the scaling factor might explain at maximum a factor of $2.2(=1.5 \times 1.49)$ overestimated variability. The different resolution of the SCIAMACHY measurements $\left(60 \times 30 \mathrm{~km}^{2}\right)$ and the model simulations $(1.8 \times 1.8 \mathrm{deg})$ also contribute to a difference in the observed and the modeled variability. Further study is needed to identify the origin of the scaling factors for $\mathrm{CO}_{2}$ and $\mathrm{O}_{2}$. Also the averaging kernels need to be taken into account when comparing with reference data. The factor of 2.2 however can only partially explain the observed variability. At least a factor of 2 higher observed variability still needs to be explained.

In the following we present a detailed comparison of the retrieved $\mathrm{XCO}_{2}$ with TM3 model simulations. TM3 3.8 (Heimann and Körner, 2003) is a three-dimensional global atmospheric transport model for an arbitrary number of active or passive tracers. It uses re-analyzed meteorological fields from the National Center for Environmental Prediction (NCEP) or from the ECMWF re-analysis. The modeled processes comprise tracer advection, vertical transport due to convective clouds and turbulent vertical transport by diffusion. Available horizontal resolutions range from $8 \times 10 \mathrm{deg}$ to $1.1 \times 1.1 \mathrm{deg}$. In this case, TM3 was run with a resolution of $1.8 \times 1.8 \mathrm{deg}$ and 28 layers, and the meteorology fields were derived from the NCEP/DOE AMIP-II reanalysis. $\mathrm{CO}_{2}$ source/sink fields for the ocean originate from Takahaschi et al. (2002), for anthropogenic sources from the EDGAR 3.2 database and for the biosphere from the BIOME-BGC model (Thornton et al., 2002) with inclusion of a simple parameterization of the diurnal cycle in photosynthesis and respiration. For SCIAMACHY the averages have been computed using only the cloud free pixels with a $\mathrm{XCO}_{2}$ error of less than 10\%. Shown in Fig. 6 are only the data over land because of the problems with measuring over the ocean in the nearinfrared (see Sect. 5).

For SCIAMACHY Fig. 6 shows absolute column averaged mixing ratios of $\mathrm{CO}_{2}$ in the range $335-385$ ppmv. For TM3 "uncalibrated" $\mathrm{XCO}_{2}$-offsets are shown which are in the range $0-13.7 \mathrm{ppmv}$. These offsets do not include the (current) background concentration of $\mathrm{CO}_{2}$. Therefore, not the absolute values but only the variability in space and time should be compared. The model simulations show low $\mathrm{CO}_{2}$ columns (compared to the mean column) over the Northern Hemisphere in July 2003 compared to higher values in May and September. This is mainly due to uptake of $\mathrm{CO}_{2}$ by the biosphere which results in minimum columns around July. Qualitatively the SCIAMACHY data show a similar time dependence with also lower columns in July compared to May and September. Thus the general time dependence of the SCIAMACHY retrievals is consistent with the model simulations. 

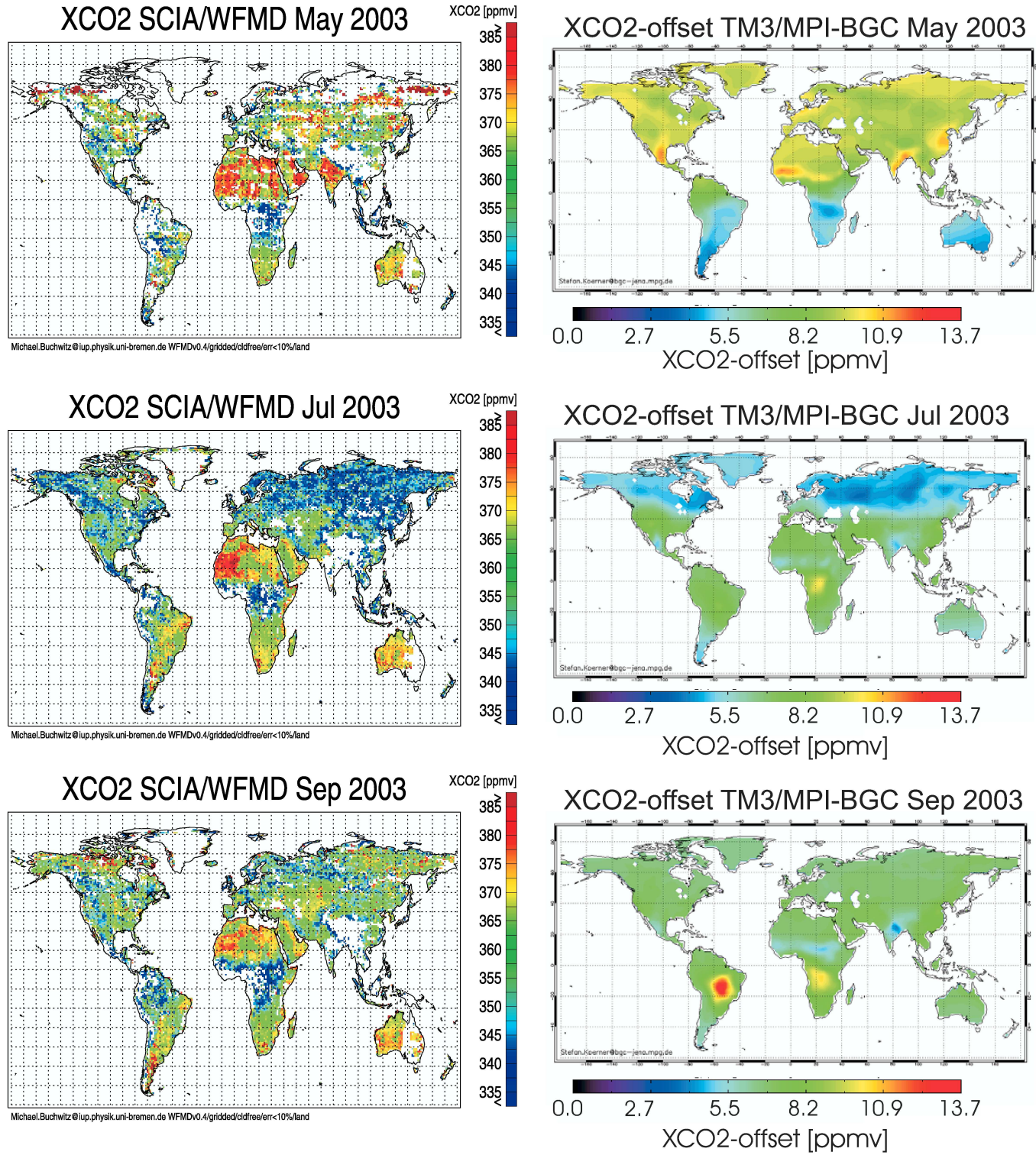

Fig. 6. Comparison of SCIAMACHY $\mathrm{XCO}_{2}$ (left) with TM3 model simulations (right). For SCIAMACHY all cloud free measurements over land have been averaged where the $\mathrm{CO}_{2}$ column fit error is less than $10 \%$. For TM3 monthly averaged $\mathrm{XCO}_{2}$-offsets are shown. These offsets do not include the background concentration of $\mathrm{CO}_{2}$. Therefore, only the spatial and temporal variability should be compared. Two different scales have been used, one for SCIAMACHY ( $\pm 25 \mathrm{ppmv})$ and one for the model simulations $( \pm 6.85$ ppmv), to consider the $3-4$ times higher variability of the SCIAMACHY data compared to the model data.

Figure 6 shows that over large parts of the (mostly western) Sahara SCIAMACHY sees "plumes" of relatively high $\mathrm{CO}_{2}$ (red colored areas) not present in the model simulations. These few percent too high $\mathrm{CO}_{2}$ mixing ratios may result from the high surface reflectivity over the Sahara in combination with aerosol variability. This is qualitatively consistent with the analysis of Houweling et al. (2005) who performed a detailed study on the impact of aerosols and albedo on SCIAMACHY $\mathrm{CO}_{2}$ column retrievals. We are optimistic that this problem can be substantially reduced in future versions of our retrieval algorithm which currently only considers first order effects of albedo and aerosol variability (mainly by including a polynomial in our WFM-DOAS fit). Currently, for the radiative transfer simulations, a constant surface albedo of 0.1 is assumed and only one aerosol scenario. According to the error analysis presented in Buchwitz et al. (2005) the $\mathrm{XCO}_{2}$ error is estimated to be $+4.5 \%$ ( $16 \mathrm{ppmv}$ overestimation) if the albedo is 0.3 instead of 0.1 (for a solar zenith angle of $50^{\circ}$ ). Depending on the aerosol scenario and on a number of other parameters the actual error might be 

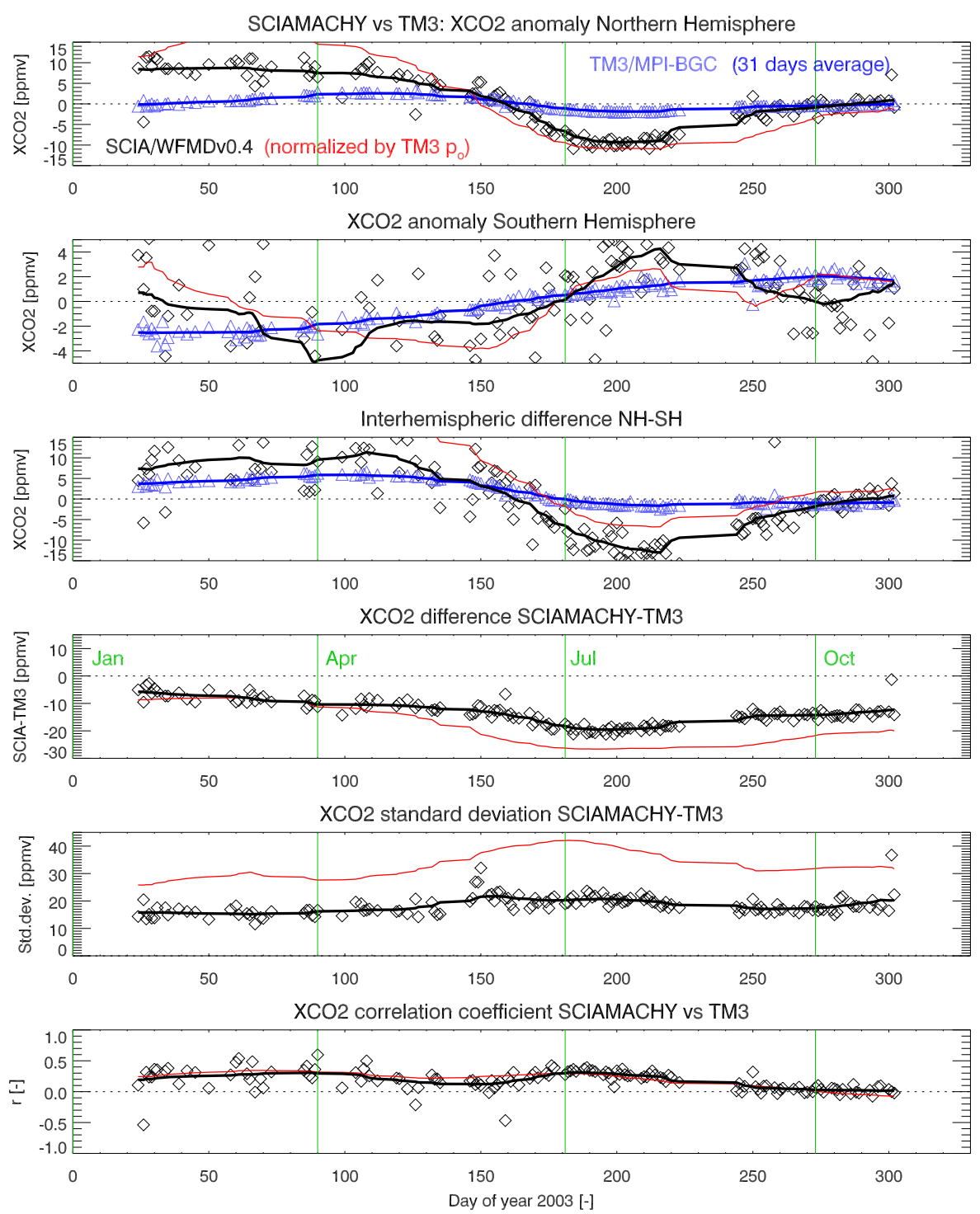

Fig. 7. Comparison of daily gridded $\mathrm{XCO}_{2}$ from SCIAMACHY (considering only cloud free pixels over land) with TM3 model simulations (considering only those gridboxes for a given day where also observations have been made). First three panels: Black diamonds: SCIAMACHY daily average. Blue triangles: as black diamonds but for TM3. Solid lines: 31 days running means of the daily data. Red lines: as black lines but using the TM3 surface pressure (instead of the retrieved $\mathrm{O}_{2}$ column) to convert the retrieved $\mathrm{CO}_{2}$ column to $\mathrm{XCO}_{2}$. The top panel shows a comparison of northern hemispheric averages, the middle panel a comparison of southern hemispheric averages, and the bottom panel a comparison of the inter-hemispheric differences (northern hemispheric mean minus southern hemispheric mean). Last three panels: The top panel shows the mean difference (SCIA-TM3) for the global data, the middle panel the standard deviation of this difference, and the bottom panel Pearson's linear correlation coefficient for the two data sets.

somewhat higher or lower. This indicates that the high values seen by SCIAMACHY over the Sahara may be explained by retrieval algorithm limitations as the current version does not take albedo and aerosol variations fully into account.

To provide more confidence that the uptake (and release) of $\mathrm{CO}_{2}$ by the biosphere can be observed with SCIAMACHY, the year $2003 \mathrm{XCO}_{2}$ data set has been investigated in more detail. This is important, because the estimated retrieval errors are on the same order as the few ppmv $\mathrm{XCO}_{2}$ variations shown by the model. It has to be made sure that the observed $\mathrm{XCO}_{2}$ modulations are not an artifact resulting from, e.g., solar zenith angle dependent errors. Figure 7 shows a detailed comparison of the daily data as well as for time averaged data (using a 31 days running mean) for the entire year 2003 data set.

Before we discuss the first three panels we will discuss the bottom part of Fig. 7. The last three panels show the mean difference between SCIAMACHY (black) and TM3 (blue), 
the standard deviation of the difference, and the correlation coefficient. The mean difference is in the range -5 ppmv to -20 ppmv ( $-1.5 \%$ to $-5.5 \%$; low bias of SCIAMACHY), the standard deviation is in the range 15-20 ppmv ( 4-5\%), and the correlation coefficient is typically around 0.3 . The red lines correspond to the same comparison, except that the $\mathrm{CO}_{2}$ columns have been normalized by the surface pressure of the TM3 model to obtain the observed $\mathrm{XCO}_{2}$. As one can see, using the models surface pressure instead of the retrieved $\mathrm{O}_{2}$ column leaves the results either nearly unchanged (correlation coefficient) or results in larger differences (larger bias and standard deviation). From this one can conclude that normalizing the $\mathrm{CO}_{2}$ by $\mathrm{O}_{2}$ gives better results than normalization by model surface pressure although the normalization by $\mathrm{O}_{2}$ is not unproblematic because the large spectral difference between the $\mathrm{O}_{2}$ A band $(760 \mathrm{~nm})$ and the $\mathrm{CO}_{2}$ band $(1580 \mathrm{~nm})$ does not guarantee perfect cancellation of errors.

The first three panels of Fig. 7 show a comparison of hemispheric averages of the two data sets. The data are plotted as anomalies, i.e., each data set has a mean value of zero. The SCIAMACHY data are shown in black, the TM3 data in blue. The symbols refer to daily mean values and the lines to time averaged data (31 days running means). The red lines have the same meaning as described in the previous paragraph $\left(\mathrm{XCO}_{2}\right.$ from SCIAMACHY obtained by normalizing with TM3 surface pressure). The top panel shows a comparison of northern hemispheric averages, the second panel the comparison for the Southern Hemisphere, and the third panel a comparison of the inter-hemispheric difference (NH$\mathrm{SH})$. Let us focus on the time averaged data (solid lines). In the top panel the blue lines show the time dependence of the model $\mathrm{XCO}_{2}$. During the first half of the year (until around day 160) the model $\mathrm{XCO}_{2}$ is mostly larger than the average (which is zero), during the second half of the year the model $\mathrm{XCO}_{2}$ is mostly lower than the average. The minimum occurs end of July / beginning of August, after the peak in the Northern Hemisphere land biosphere uptake. The SCIAMACHY data (black solid line) show a similar time dependence (except at the beginning of the year where the observed $\mathrm{XCO}_{2}$ is rather constant but the model $\mathrm{XCO}_{2}$ slightly increases with time). Both curves cross the zero line at nearly the same day. The main difference is the amplitude of the sinusoidal time dependence, which is about a factor of four larger for SCIAMACHY (8 ppmv compared to 2-3 ppmv). The second panel shows the same comparison but for the Southern Hemisphere. The main difference with respect to the Northern Hemisphere is the expected six-month shift and the much smaller amplitude of the time dependence of the observed $\mathrm{XCO}_{2}$ (which is also "noisier", i.e., shows more deviation from the smooth sinusoidal behavior of the model simulations). This is most probably due to less available data points for the Southern Hemisphere which contains less land surfaces than the Northern Hemisphere (remember that only data over land are compared). Over the Southern Hemisphere the amplitude of the observed variability is roughly
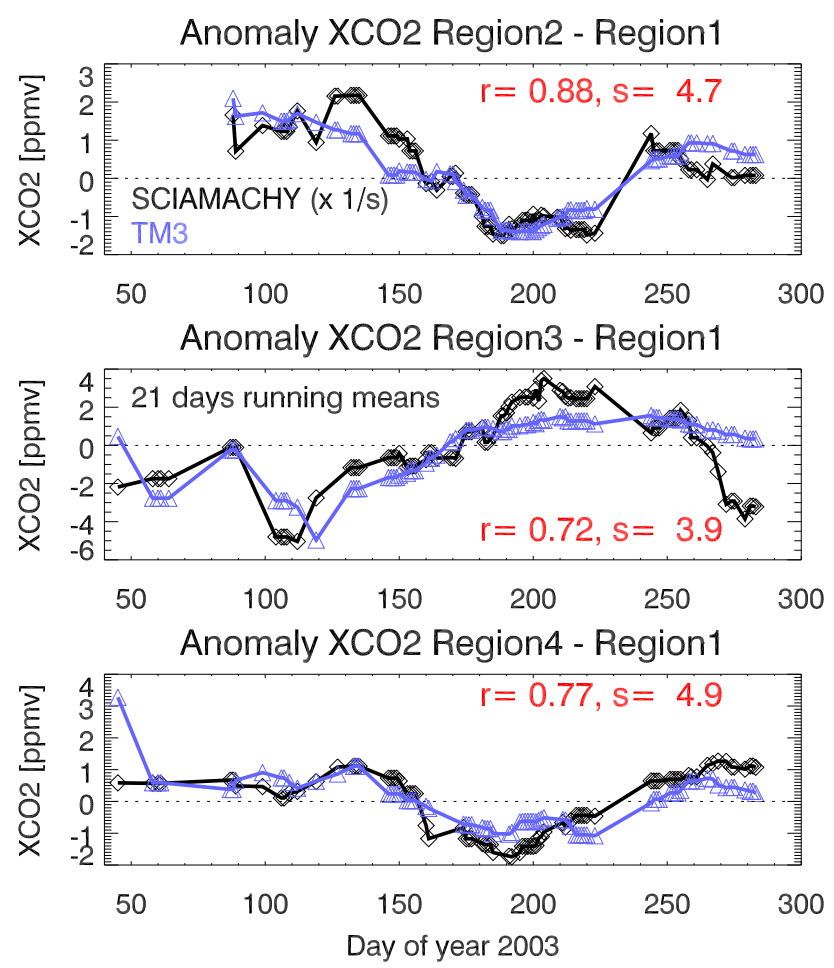

Fig. 8. Comparison of time series of regional $\mathrm{XCO}_{2}$ differences (shown as anomalies, i.e., with a mean value of zero). Top panel: The SCIAMACHY data (shown in black) have been obtained as follows: Two regions have been defined (each 20-deg latitude $\times$ 20-deg longitude) which are denoted region 1 (the reference region) and region 2 (both regions are shown in Fig. 9 where, for example, the reference region is shown as green rectangle). For each region its daily average $\mathrm{XCO}_{2}$ has been determined (considering only measurements over land). The daily time series for the reference region has been subtracted from the time series of region 2 (only if data were available for both regions; if not the day was ignored). The time series of the $\mathrm{XCO}_{2}$ difference has been smoothed (21 days running mean). Finally, the mean of the time series has been subtracted. The blue curve has been obtained by applying the same procedure to the TM3 model data. Annotation: $r$ denotes Pearson's linear correlation coefficient and $s$ is a scaling factor obtained from a linear least squares fit of the SCIAMACHY time series to the TM3 time series ( $s=4.7$ means that the SCIAMACHY $\mathrm{XCO}_{2}$ anomaly time series has to be divided by 4.7 to match the TM3 time series). The middle and the bottom panels show the corresponding time series for two other regions denoted regions 3 and 4 (shown in Fig. 9).

in agreement with the modeled variability. The third panel shows the observed and modeled inter-hemispheric $\mathrm{XCO}_{2}$ difference.

The first three panels of Fig. 7 show that the SCIAMACHY observations are significantly correlated with the model results. The time dependence of the observed $\mathrm{XCO}_{2}$ cannot be explained by a solar zenith angle dependent error. Over the Northern Hemisphere the minimum solar zenith 
XCO2 SCIA/WFMDv0.4 vs TM3/MPI-BGC: Regional Differences: $r$

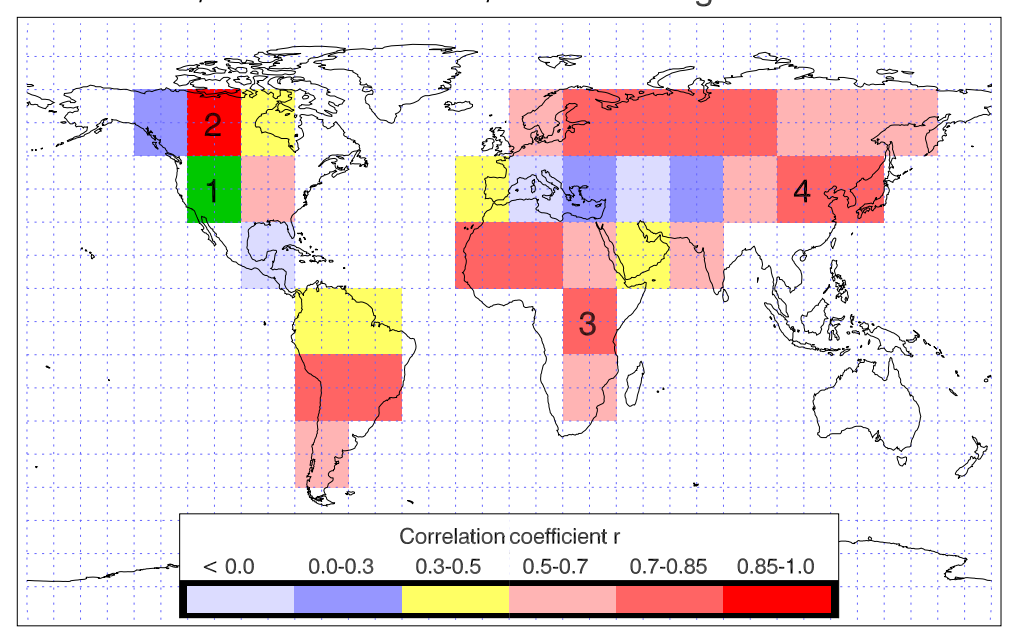

XCO2 SCIA/WFMDv0.4 vs TM3/MPI-BGC: Regional Differences: s

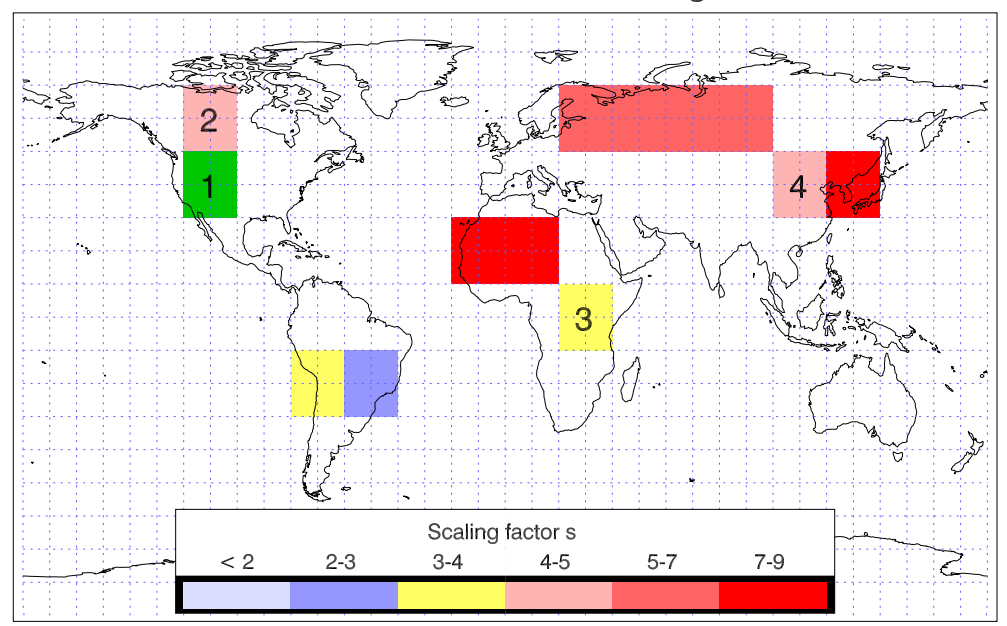

Fig. 9. Correlation coefficient $r$ (top panel) and scaling factor $s$ (bottom panel) for SCIAMACHY and TM3 time series of regional XCO 2 differences (see Fig. 8 for a detailed explanation). The green area indicates the reference region (region 1). Details for regions $2-4$ are shown in Fig. 8. The correlation coefficient is only shown for those regions where the final time series comprises at least 70 days. The scaling factor (bottom panel) is only shown for a subset of the regions shown in the top panel, namely only for regions where the correlation coefficient is larger than 0.7 .

angle occurs at summer solstice (21 June; around day 170), i.e., close to the day where the $\mathrm{XCO}_{2}$ values cross the zero line and change sign. A solar zenith angle dependent error would be symmetric around summer solstice, but the curves are anti-symmetric with respect to this day. This means that the observed $\mathrm{XCO}_{2}$ is not significantly influenced by a solar zenith angle dependent error. A significant error due to the changing solar zenith angle was not to be expected as the solar zenith angle dependence of the radiative transfer is explicitely taken into account for WFM-DOAS retrievals. Similar arguments can be given for atmospheric temperature related errors. Temperature variability is taken into account because a temperature weighting function is included in the WFM-DOAS fit.
Now we will focus on the regional scale. A comparison between observed and modeled $\mathrm{XCO}_{2}$ for regions of size 20 deg latitude times $20 \mathrm{deg}$ longitude yields similar sinusoidal curves (not shown here) as displayed in the first two panels of Fig. 7 for the hemispheric averages. In order to better highlight regional differences we have compared differences between time series from two regions. Typical results are shown in Fig. 8. We have selected a smaller interval for the time averaging ( 21 days) compared to the interval used for Fig. 7 (31 days) to better display the regional differences.

The top panel of Fig. 8 shows the observed time series (in black) and the model time series (in blue). These curves are the difference of the time series of two regions, region 2 and region 1 (region 1 is denoted the reference region in the 
following). The spatial positions of both regions (and of the regions 3 and 4 investigated in the remaining two panels) are shown in Fig. 9. As in Fig. 7 all curves are shown as anomalies. As can be seen, the measured and the modeled curve are significantly correlated $(r=0.88)$. The main difference is the amplitude. The SCIAMACHY curve has been divided by a scaling factor $s$, which is 4.7 . This value has been determined by a linear least-squares fit. The middle and the bottom panels show the same comparison for two other regions (shown in Fig. 7) but using the same reference region (region 1). Figure 7 shows the extension of this analysis to the entire globe (but restricted to land surfaces) using the same region 1 as reference region as used for the detailed results shown in Fig. 8. Shown in the top panel, which displays the correlation coefficient $r$ (see Fig. 8), are only those regions where at least 70 days with measurements were available in this region and (for the same days) also in the reference region. The bottom panel show the scaling factor $s$ (see Fig. 8) for the sub-set of the regions shown in the top panel where the correlation coefficient is larger than 0.7 (otherwise the scaling does not make too much sense). The top panel shows that significant correlations exist for most regions between observed and modelled $\mathrm{XCO}_{2}$. The bottom panel shown that the scaling factor is mostly in the range 3-7 and always less than 9. This analysis confirms earlier results obtained with the same data set also indicating that the retrieved $\mathrm{XCO}_{2}$ variability is typically significantly larger than the variability of the model simulations (typically larger than a factor of 2 which might be explained by the averaging kernels and the applied scaling factor). This analysis also indicates that SCIAMACHY seems is able to capture regional $\mathrm{XCO}_{2}$ differences which is important for the main application of these measurements, namely the detection and quantification of regional sources and sinks of $\mathrm{CO}_{2}$.

\section{Conclusions}

Nearly one year (2003) of SCIAMACHY nadir measurements have been processed with the WFM-DOAS retrieval algorithm (v0.4, for methane also v0.41) to generate a number of data products: vertical columns of $\mathrm{CO}, \mathrm{CH}_{4}$, and $\mathrm{CO}_{2}$. In addition, $\mathrm{O}_{2}$ columns have been retrieved to compute dry air column averaged mixing ratios for the relatively well-mixed greenhouse gases $\mathrm{CH}_{4}$ and $\mathrm{CO}_{2}$, denoted $\mathrm{XCH}_{4}$ and $\mathrm{XCO}_{2}$, respectively. The data products have been compared with independent measurements ( $\mathrm{CO}$ from MOPITT) and model simulations (for $\mathrm{CH}_{4}$ and $\mathrm{CO}_{2}$ ).

For the $\mathrm{CO}$ columns the agreement with MOPITT is mostly within 30\% (Buchwitz et al., 2004). SCIAMACHY detects enhanced concentrations of $\mathrm{CO}$ due to biomass burning similar as MOPITT. SCIAMACHY seems to systematically overestimate the CO columns over large parts of the Southern Hemisphere at least for certain months where MOPITT sees systematically lower columns in the Southern
Table 1. Current estimates of precision and accuracy of the SCIAMACHY/WFM-DOAS v0.4x vertical column data products over land. The WFM-DOAS products are partially based on scaled initially retrieved columns (the scaling factors are: 0.5 for $\mathrm{CO}, 1.27$ for $\mathrm{CO}_{2}, 0.85$ for $\mathrm{O}_{2}$, no scaling for methane).

\begin{tabular}{llll}
\hline $\begin{array}{l}\text { Data } \\
\text { product }\end{array}$ & $\begin{array}{l}\text { Horizontal } \\
\text { resolution } \\
{\left[\mathrm{km}^{2}\right]}\end{array}$ & $\begin{array}{l}\text { Estimated } \\
\text { precision } \\
\text { (scatter) } \\
{[\%]}\end{array}$ & $\begin{array}{l}\text { Estimated } \\
\text { accuracy } \\
\text { (bias) } \\
{[\%]}\end{array}$ \\
\hline $\mathrm{CO}(\mathrm{v} 0.4)$ & $30 \times 120$ & $10-20$ & $\begin{array}{l}10-30 \\
\text { (mostly positive) }\end{array}$ \\
\hline $\mathrm{XCH}_{4}(\mathrm{v} 0.4)$ & $30 \times 120$ & $1-6$ & $\begin{array}{l}2-15 \\
\text { (mostly negative) }\end{array}$ \\
$\mathrm{XCH}_{4}(\mathrm{v} 0.41)$ & $30 \times 120$ & $1-4$ & $2-5$ \\
\hline $\mathrm{XCO}_{2}(\mathrm{v} 0.4)$ & $30 \times 60$ & $1-4$ & $2-5$ \\
\hline
\end{tabular}

Hemisphere compared to the Northern Hemisphere. This discrepancy is most probably related to the difficulty of accurately fitting the weak CO lines covered by SCIAMACHY (see Sect. 9).

The WFM-DOAS Version 0.4 methane columns have a time dependent bias of up to about $-15 \%$ related to ice buildup on the channel 8 detector. Using a simple bias correction an improved methane data product (v0.41) has been generated. The comparison with model simulations shows agreement within a few percent (mostly within 5\%). The comparison indicates that SCIAMACHY can detect elevated methane columns resulting from emissions from surface sources such as rice fields and wetlands over India, southeast Asia and central Africa. Similar findings have been reported in Frankenberg et al. (2005c).

The (scaled) WFM-DOAS Version $0.4 \mathrm{CO}_{2}$ columns show agreement with model simulations within a few percent (mostly within 5\%). The comparison indicates that SCIA$\mathrm{MACHY}$ is able to detect low columns of $\mathrm{CO}_{2}$ resulting from uptake of $\mathrm{CO}_{2}$ over the Northern Hemisphere when the vegetation is in its main growing season. Over highly reflecting surfaces such as over the Sahara SCIAMACHY seems to systematically overestimate the column averaged mixing ratio of $\mathrm{CO}_{2}$ by a few percent most probably because of limitations of the current version of the retrieval algorithm (simplified treatment of albedo and aerosol variability).

A summary of our findings from the comparisons with independent data shown here and elsewhere (Buchwitz et al., 2004, 2005; Gloudemans et al., 2004; de Maziere et al., 2004; Dils et al., 2005; Sussmann et al., 2005; Sussmann and Buchwitz, 2005; Warneke et al., 2005) is given in Table 1 which shows our current best estimates of precision and accuracy of our v0.4x data products.

Our future work will focus on identifying the reasons for the observed biases and to improve the accuracy of the data 
products. This work has already started an the latest status is shortly summarized in the next section.

\section{Outlook}

Recently (May 2005), we have reprocessed the year 2003 data for $\mathrm{CO}$ and $\mathrm{XCH}_{4}$ with a new version (v0.5) of the WFM-DOAS retrieval algorithm. Our initial analysis indicates that at least some of the major problems identified for the v0.4x data products discussed in this paper have been solved. For example, the v0.5 CO is retrieved from an optimized fitting window and is not scaled any more (the v0.4 product was scaled with the factor 0.5 ). The $\mathrm{v} 0.5 \mathrm{CO}$ is normalized with the methane column retrieved from the same fitting window. This approach results (at least partially) in canceling of errors which are common to both gases (e.g., errors due to slit function changes caused by the ice issue, partial clouds, aerosols). For v0.5 $\mathrm{XCH}_{4}$ the methane column is obtained from channel 6 which is not affected by the ice issue. More details concerning the v0.5 $\mathrm{CO}$ and methane data products are given in a separate paper (de Beek et al., 2005).

Acknowledgements. We thank ESA and DLR for making available the SCIAMACHY Level 1 data. We thank the MOPITT teams at NCAR and University of Toronto for the MOPITT Level 2 Version 3 data which have been obtained via the NASA Langley DAAC. Funding for this study came from the German Ministry for Research and Education (BMBF) via DLR-Bonn and GSF/PT-UKF, the European Commission (5th FP on Energy, Environment and Sustainable Development, Contract no. EVG1-CT-2002-00079, project EVERGREEN), from ESA (via GMES project PROMOTE) and from the University and the State of Bremen. We acknowledge exchange of information within the European Commission (EC) Network of Excellence ACCENT.

Edited by: U. Platt

\section{References}

Bergamaschi, P., Krol, M., Dentener, F., Vermeulen, A., Meinhardt, F., Graul, R., Peters, W., and Dlugokencky, E. J.: Inverse modelling of national and European $\mathrm{CH}_{4}$ emissions using the atmospheric zoom model TM5, Atmos. Chem. Phys., 5, 2431-2460, 2005,

SRef-ID: 1680-7324/acp/2005-5-2431.

Bergamaschi, P., Hein, R., Heimann, M., and Crutzen, P. J.: Inverse modeling of the global $\mathrm{CO}$ cycle, 1 . Inversion of $\mathrm{CO}$ mixing ratios, J. Geophys. Res., 105, 1909-1927, 2000.

Bovensmann, H., Buchwitz, M., Frerick, J., Hoogeveen, R., Kleipool, Q., Lichtenberg, G., Noël, S., Richter, A., Rozanov, A., Rozanov, V. V., Skupin, J., von Savigny, C., Wuttke, M., and Burrows, J. P.: SCIAMACHY on ENVISAT: In-flight optical performance and first results, in: Remote Sensing of Clouds and the Atmosphere VIII, edited by: Schäfer, K. P., Comèron, A., Carleer, M. R., and Picard, R. H., vol. 5235 of Proceedings of SPIE, 160-173 (PDF file available from WFM-DOAS web site, see end of Sect. 9), 2004.

Bovensmann, H., Burrows, J. P., Buchwitz, M., Frerick, J., Noël, S., Rozanov, V. V., Chance, K. V., and Goede, A.: SCIAMACHY Mission Objectives and Measurement Modes, J. Atmos. Sci., 56, 127-150, 1999.

Buchwitz, M., de Beek, R., Burrows, J. P., Bovensmann, H., Warneke, T., Notholt, J., Meirink, Goede, A. P. H., Bergamaschi, P., Körner, S., Heimann, M., and Schulz, A.: Atmospheric methane and carbon dioxide from SCIAMACHY satellite data: Initial comparison with chemistry and transport models, Atmos. Chem. Phys., 5, 941-962, 2005,

SRef-ID: 1680-7324/acp/2005-5-941.

Buchwitz, M., de Beek, R., Bramstedt, K., Noël, S., Bovensmann, H., and Burrows, J. P.: Global carbon monoxide as retrieved from SCIAMACHY by WFM-DOAS, Atmos. Chem. Phys., 4, 19451960, 2004,

SRef-ID: 1680-7324/acp/2004-4-1945.

Buchwitz, M. and Burrows, J. P.: Retrieval of $\mathrm{CH}_{4}, \mathrm{CO}$, and $\mathrm{CO}_{2}$ total column amounts from SCIAMACHY near-infrared nadir spectra: Retrieval algorithm and first results, in: Remote Sensing of Clouds and the Atmosphere VIII, edited by: Schäfer, K. P., Comèron, A., Carleer, M. R., and Picard, R. H., vol. 5235 of Proceedings of SPIE, 375-388 (PDF file available from WFMDOAS web site, see end of Sect. 9), 2004.

Buchwitz, M., Rozanov, V. V., and Burrows, J. P.: A near infrared optimized DOAS method for the fast global retrieval of atmospheric $\mathrm{CH}_{4}, \mathrm{CO}, \mathrm{CO}_{2}, \mathrm{H}_{2} \mathrm{O}$, and $\mathrm{N}_{2} \mathrm{O}$ total column amounts from SCIAMACHY/ENVISAT-1 nadir radiances, J. Geophys. Res., 105, 15 231-15 246, 2000a.

Buchwitz, M., Rozanov, V. V., and Burrows, J. P.: A correlated-k distribution scheme for overlapping gases suitable for retrieval of atmospheric constituents from moderate resolution radiance measurements in the visible/near-infrared spectral region, J. Geophys. Res., 105, 15 247-15 262, 2000 b.

Burrows, J. P., Hölzle, E., Goede, A. P. H., Visser H., and Fricke, W.: SCIAMACHY - Scanning Imaging Absorption Spectrometer for Atmospheric Chartography, Acta Astronautica, 35(7), 445-451, 1995.

de Beek, R., Buchwitz, M., Noël, S., Burrows, J. P., Bovensmann, H., Bruns, M., Bremer, H., Bergamaschi, P., Körner, S., and Heimann, H.: Atmospheric carbon gases retrieved from SCIAMACHY by WFM-DOAS: improved global $\mathrm{CO}$ and $\mathrm{CH}_{4}$ and initial verification of $\mathrm{CO}_{2}$ over Park Falls $\left(46^{\circ} \mathrm{N}, 90^{\circ} \mathrm{W}\right)$, Atmos. Chem. Phys. Discuss., accepted, 2005.

Deeter, M. N., Emmons, L. K., Francis, G. L., Edwards, D. P., Gille, J. C., Warner, J. X., Khattatov, B., Ziskin, D., Lamarque, J.-F., Ho, S.-P., Yuding, V., Attie, J.-L., Packman, D., Chen, J., Mao, D., and Drummond, J. R.: Operational carbon monoxide retrieval algorithm and selected results for the MOPITT instrument, J. Geophys. Res., 108, 4399-4409, 2003.

de Mazière, M., Barret, B., Blumenstock, T., Buchwitz, M., de Beek, R., Demoulin, P., Fast, H., Gloudemans, A., Griesfeller, A., Griffith, D., Ionov, D., Janssens, K., Jones, N., Mahieu, E., Melleqvist, J., Mittermeier, R. L., Notholt, J., Rinsland, C., Schrijver, H., Schultz, A., Smale, D., Strandberg, A., Strong, K., Sussmann, R., Warneke, T., and Wood, S.: Comparison between SCIAMACHY scientific products and ground-based FTIR data for total columns of $\mathrm{CO}, \mathrm{CH}_{4}$, and $\mathrm{N}_{2} \mathrm{O}$, in: Proceedings of 
the Second Workshop on the Atmospheric Chemistry Validation of ENVISAT (ACVE-2), ESA/ESRIN, Frascati, Italy, 3-7 May 2004, ESA SP-562 (on CD), 2004.

Dils, B., de Maziere, M., Blumenstock, T., et al.: Comparison between SCIAMACHY and ground-based FTIR data for total columns of $\mathrm{CO}, \mathrm{CH}_{4}, \mathrm{CO}_{2}$ and $\mathrm{N}_{2} \mathrm{O}$, Atmos. Chem. Phys. Discuss., 5, 2677-2717, 2005,

SRef-ID: 1680-7375/acpd/2005-5-2677.

Emmons, L. K., Deeter, M. N., Gille, J. C., Edwards, D. P., Attiè, J.-L., Warner, J., Ziskin, D., Francis, G., Khattatov, B., Yudin, V., Lamarque, J.-F., Ho, S.-P., Mao, D., Chen, J. S., Drummond, J., Novelli, P., Sachse, G., Coffey, M. T., Hannigan, J. W., Gerbig, C., Kawakami, S., Kondo, Y., Takegawa, N., Schlager, H., Baehr, J., and Ziereis, H.: Validation of Measurements of Pollution in the Troposphere (MOPITT) CO retrievals with aircraft in situ profiles, J. Geophys. Res., 109, D03309, doi:10.1029/2003JD004101, 2004.

Frankenberg, C., Platt, U., and Wagner, T.: Iterative maximum a posteriori (IMAP-)DOAS for retrieval of strongly absorbing trace gases: Model studies for $\mathrm{CH}_{4}$ and $\mathrm{CO}_{2}$ retrieval from nearinfrared spectra of SCIAMACHY onboard ENVISAT, Atmos. Chem. Phys., 5, 9-22, 2005a,

SRef-ID: 1680-7324/acp/2005-5-9.

Frankenberg, C., Platt, U., Wagner, T., Retrieval of CO from SCIAMACHY onboard ENVISAT: Detection of strongly polluted areas and seasonal patterns in global $\mathrm{CO}$ abundances, Atmos. Chem. Phys., 5, 1639-1644, 2005b,

SRef-ID: 1680-7324/acp/2005-5-1639.

Frankenberg, C., Meirink, J. F., van Weele, M., Platt, U., and Wagner, T.: Assessing methane emissions from global spaceborne observations, Science, 308, 1010-1014, 2005c.

Gloudemans, A. M. S., Schrijver, H., Straume, A. G., Aben, I., Maurellis, A. N., Buchwitz, M., de Beek, R., Frankenberg, C., Wagner, T., and Meirink, J. F.: $\mathrm{CH}_{4}$ and $\mathrm{CO}$ total columns from SCIAMACHY: Comparisons with TM3 and MOPITT, in: Proceedings of Second Workshop on the Atmospheric Chemistry Validation of ENVISAT (ACVE-2), ESA/ESRIN, Frascati, Italy, 3-7 May 2004, ESA SP-562 (on CD), 2004.

Gloudemans, A. M. S., Schrijver, H., Kleipool, Q., van den Broek, M. M. P., Straume, A. G., Lichtenberg, G., van Hess, R. M., Aben, I., and Meirink, J. F.: The impact of SCIAMACHY nearinfrared instrument calibration on $\mathrm{CH}_{4}$ and $\mathrm{CO}$ total columns, Atmos. Chem. Phys., 5, 2369-2383, 2005,

SRef-ID: 1680-7324/acp/2005-5-2369.

Heimann, M. and Körner, S.: The Global Atmospheric Tracer Model TM3, Model Description and Users Manual Release 3.8a, No. 5, Max Planck Institute for Biogeochemistry (MPI-BGC), Jena, Germany, 2003.

Houweling, S., Kaminski, T., and Dentener, F., Lelieveld, J., and Heimann, M.: Inverse modeling of methane sources and sinks using the adjoint of a global transport model, J. Geophys. Res., 105 (D21), 26 137-26 160, 1999.

Houweling, S., Breon, F.-M., Aben, I., Rödenbeck, C., Gloor, M., Heimann, M., and Ciais, P.: Inverse modeling of $\mathrm{CO}_{2}$ sources and sinks using satellite data: A synthetic inter-comparison of measurement techniques and their performance as a function of space and time, Atmos. Chem. Phys., 4, 523-538, 2004,

SRef-ID: 1680-7324/acp/2004-4-523.
Houweling, S., Hartmann, W., Aben, I., Schrijver, H., Skidmore, J., Roelofs, G.-J., and Breon, F.-M.: Evidence of systematic errors in SCIAMACHY-observed $\mathrm{CO}_{2}$ due to aerosols, Atmos. Chem. Phys., 5, 3003-3013, 2005,

SRef-ID: 1680-7324/acp/2005-5-3003.

Krol, M. C., Houweling, S., Bregman, B., van den Broek, M., Segers, A., van Velthoven, P., Peters, W., Dentener, F., and Bergamaschi, P.: The two-way nested global chemistry-transport zoom model TM5: Algorithm and applications, Atmos. Chem. Phys., 5, 417-432, 2005,

SRef-ID: 1680-7324/acp/2005-5-417.

Rayner, P. J. and O'Brien, D. M.: The utility of remotely sensed $\mathrm{CO}_{2}$ concentration data in surface inversions, Geophys. Res. Lett., 28, 175-178, 2001.

Rothman, L. S., Barbe, A., Benner, D. C., Brown, L. R., CamyPeyret, C., Carleer, M. R., Chance, K., Clerbaux, C., Dana, V., Devi, V. M., Fayt, A., Flaud, J. M., Gamache, R. R., Goldman, A., Jacquemart, D., Jucks, K. W., Lafferty, W. J., Mandin, J. Y., Massie, S. T., Nemtchinov, V., Newnham, D. A., Perrin, A., Rinsland, C. P., Schroeder, J., Smith, K. M., Smith, M. A. H., Tang, K., Toth, R. A., Vander Auwera, J., Varanasi, P., and Yoshino, K.: The HITRAN molecular spectroscopic database: edition of 2000 including updates through 2001, J. Quant. Spectrosc. Radiat. Transfer, 82, 5-44, 2003.

Sussmann, R. and Buchwitz, M.: Initial validation of ENVISAT/SCIAMACHY columnar CO by FTIR profile retrievals at the ground truthing station Zugspitze, Atmos. Chem. Phys., 5, 1497-1503, 2005,

SRef-ID: 1680-7324/acp/2005-5-1497.

Sussmann, R., Stremme, W., Buchwitz, M., and de Beek, R.: Validation of ENVISAT/SCIAMACHY columnar methane by solar FTIR spectrometry at the ground-truthing station Zugspitze, Atmos. Chem. Phys., 5, 2419-2429, 2005,

SRef-ID: 1680-7324/acp/2005-5-2419.

Takahashi, T., Sutherland, S. C., Sweeney, C., Poisson, A., Metzl, N., Tilbrook, B., Bates, N., Wanninkhof, Feely, R. A., Sabine, C., Olafsson, J., and Nojiri, Y.: Global sea-air $\mathrm{CO}_{2}$ flux based on climatological surface ocean $\mathrm{pCO}_{2}$, and seasonal biological and temperature effects, Deep-Sea Research, 49, 1601-1622, 2002.

Thornton, P. E., Law, B. E., Gholz, H. L., Clark, K. L., Falge, E., Ellsworth, D. E. , Goldstein, A. H., Monson, R. H., Hollinger, D. Y., Falk, M., and Falk, J. P.: Modeling and measuring the effects of disturbance history and climate on carbon and water budgets in evergreen needleleaf forests, Agricultural and Forest Meteorology, 113, 185-222, 2002.

van Diedenhofen, B., O. P. Hasekamp, and Aben, I.: Surface pressure retrieval from SCIAMACHY measurements in the $\mathrm{O}_{2} \mathrm{~A}$ band: validation of the measurements and sensitivity on aerosols, Atmos. Chem. Phys., 5, 2109-2120, 2005,

SRef-ID: 1680-7324/acp/2005-5-2109.

Warneke, T., de Beek, R., Buchwitz, M., Notholt, J., Schulz, A., Velazco, V., and Schrems, O.: Shipborne solar absorption measurements of $\mathrm{CO}_{2}, \mathrm{CH}_{4}, \mathrm{~N}_{2} \mathrm{O}$, and $\mathrm{CO}$ and comparison with SCIAMACHY WFM-DOAS retrievals, Atmos. Chem. Phys., 5, 2029-2034, 2005,

SRef-ID: 1680-7324/acp/2005-5-2029. 